\title{
Electric Power Lines
}

Questions and Answers on Research into Health Effects

RECEIVEO

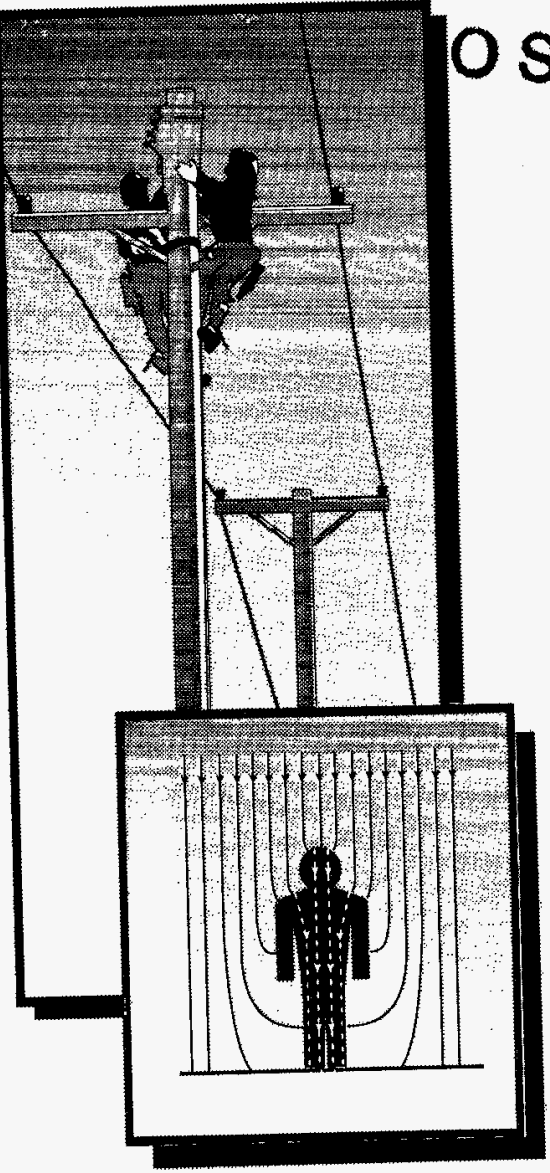

NOV 12 199

$$
\text { (1) }
$$
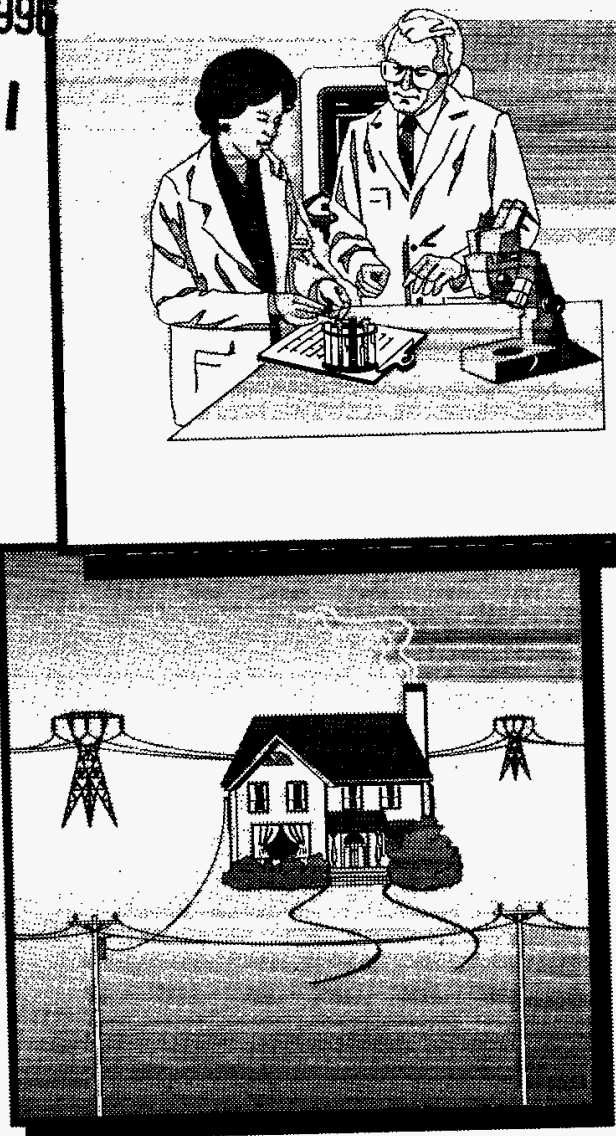

MASTER 


\section{CONTENTS}

\section{Topic}

Introduction

Electric Power Background ............................................... 2

Electric and Magnetic Fields (EMF) ................................5

Electromagnetic Spectrum ................................................ 6

Earth's EMF ............................................................. 7

Power Line and Appliance EMF ..................................... 7

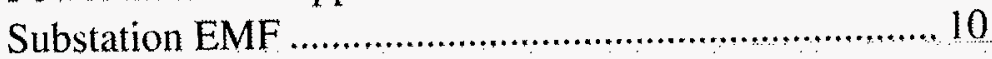

Typical EMF Exposures ................................................. 10

EMF Standards ........................................................... 13

Biological Effects of EMF ............................................ 15

Epidemiology ............................................................ 16

Power-Line Cancer Studies ............................................. 17

Swedish Study ........................................................... 19

Cancer Clusters ,.............................................................2 21

Electrical Workers ............................................................. 22

Reviews of EMF Cancer Research ....................................24

Electricity Use and Cancer Rates .................................... 25

Other Health Studies ......................................................... 26

Laboratory Studies .............................................................2

Melatonin Studies ....................................................... 28

Ongoing EMF Reșearch ................................................... 30

Living Near Transmission Lines ..................................... 30

Limiting EMF Exposures ............................................... 32

Home EMF Measurements ............................................... 33

Electrical Safety …………………………………….... 35

Nuisance Shocks .......................................................... 36

BPA's EMF Program ..................................................... 38

For More Information ……............................................. 40

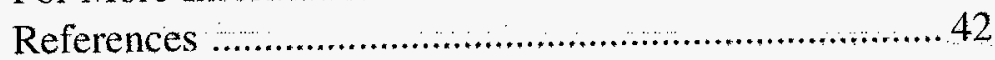




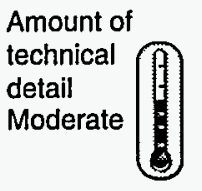

Note to readers:

This publication contains a moderate level of technical detail. See page 40 for other BPA publications on this subject.

\section{INTRODUCTION}

$\mathrm{M}$ ost people know that electric power lines, like the wiring in our homes, can cause serious electric shocks if we're not careful. Many people also want to know whether the electric and magnetic fields (EMF) produced by power lines and other electrical devices cause health effects.

The purpose of this booklet is to answer some common questions that the Bonneville Power Administration (BPA) receives about the possible effects of power lines on health. (BPA is the Pacific Northwest's Federal electric power marketing agency.) First, some basic electrical terms are defined, and electric and magnetic fields are described. Next, answers are given to several questions about recent scientific studies. Some important information about electrical safety follows. We then describe how BPA is addressing public concerns about potential health effects of power lines. The last section tells you how to obtain more detailed information about the health and safety issues summarized in this booklet.

\section{MASTER}

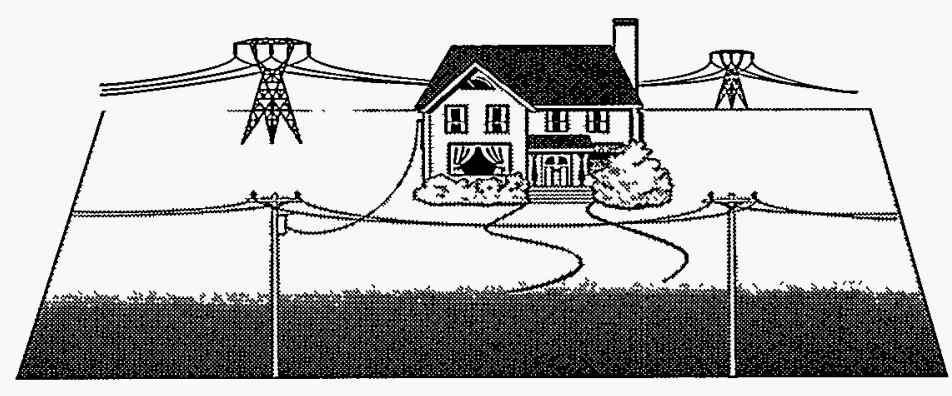

DISTRIBUTION OF THIS DOCUMENT IS UNLIMITED

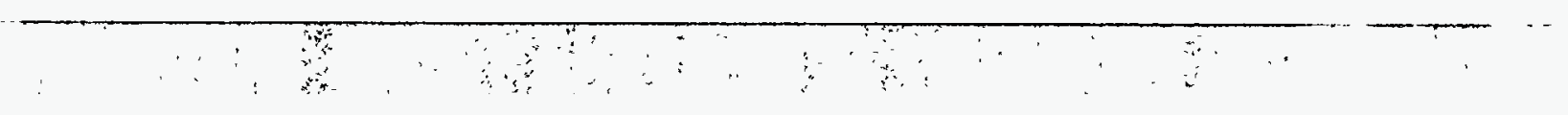




\section{BACKGROUND INFORMATION}

\section{Electric Power Basics}

This booklet uses six basic electrical termsconductor, current, voltage, load, power, and circuit. The conductor is the wire you see between power poles or towers; it carries the electricity. Current is the movement of electrons in the conductor (right). Voltage is the electric force that causes current in a conductor. Load is the electric power needed by homes and businesses. When a conductor energized with voltage is connected to a load, a circuit is completed and current will flow. Electrical terms are summarized on page 3 in a comparison with more familiar examples involving water.

\section{Electric Power Facilities}

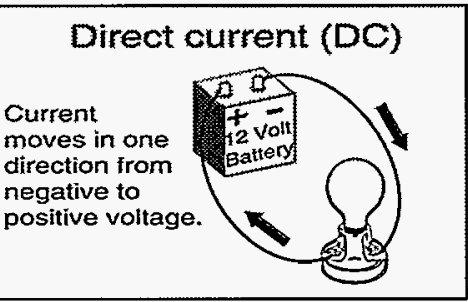

There are two basic types of power lines: transmission lines and distribution lines. Transmission lines are high-voltage power lines. The high voltage allows electric power to be carried efficiently over long distances from electrical generation facilities to substations near urban areas. BPA uses mostly alternating current $(\mathrm{AC})$ transmission lines operating at voltages of $115 \mathrm{kV}, 230 \mathrm{kV}$, and $500 \mathrm{kV}$ ( $1 \mathrm{kV}$ or kilovolt $=1000$ volts). BPA also operates one of only six direct current (DC) transmission lines in the U.S.

Utilities use lower-voltage distribution lines to bring power from substations to businesses and

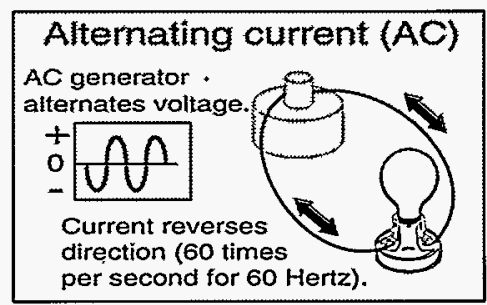

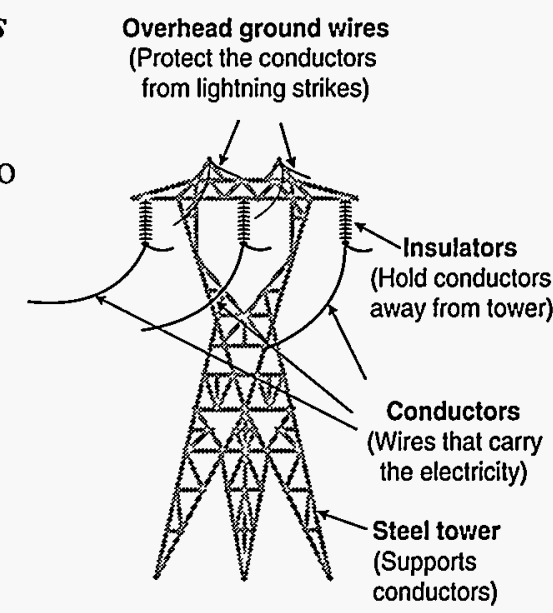

Typical Transmission Line 


\section{DISCLAIMER}

This report was prepared as an account of work sponsored by an agency of the United States Government. Neither the United States Government nor any agency thereof, nor any of their employees, makes any warranty, express or implied, or assumes any legal liability or responsibility for the accuracy, completeness, or usefulness of any information, apparatus, product, or process disclosed, or represents that its use would not infringe privately owned rights. Reference herein to any specific commercial product, process, or service by trade name, trademark, manufacturer, or otherwise does not necessarily constitute or imply its endorsement, recommendation, or favoring by the United States Government or any agency thereof. The views and opinions of authors expressed herein do not necessarily state or reflect those of the United States Government or any agency thereof. 


\section{DISCLAIMER}

Portions of this document may be illegible in electronic image products. Images are produced from the best available original document. 


\section{Electrical Terms}

\section{Familiar Comparisons}

Voltage. Electrical pressure, the potentilal to do work. Measured in volts $(V)$ or in kilovolts (kV). $1 \mathrm{kV}=1000$ volts.

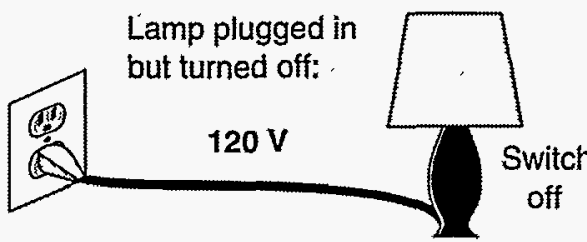

Current. The movement of electric charge (e.g. electrons). Measured in Amperes (A).

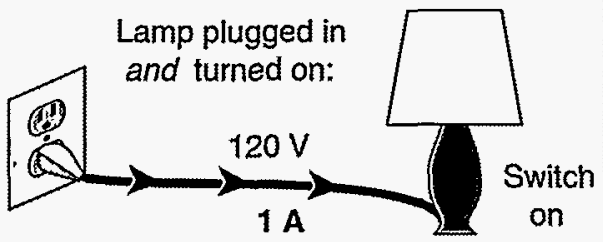

Power. The product of volts and current. Measured in watts $(W)$. In the above example:

$$
120 \mathrm{~V} \times 1 \mathrm{~A}=120 \mathrm{~W}
$$

You can raise the voltage and lower the current and produce the same power:

$$
240 \mathrm{~V} \times 0.5 \mathrm{~A}=120 \mathrm{~W}
$$

Conductor. Material that will carry electric current.

Excellent conductor:

Fair conductor: Non-conductor (an insulator):
Copper Human body

Rubber
Hose connected to an open faucet 3 but with the nozzle turned off.

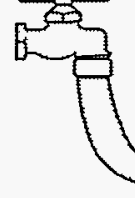

Water pressure in hose.

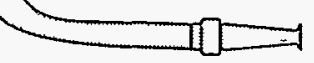

Nozzle closed.

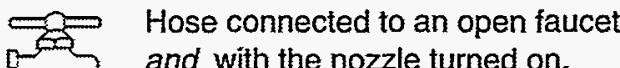
and with the nozzle turned on.

Moving water in hose.

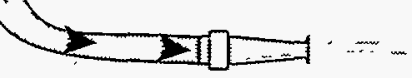

Nozzle open.

Low pressure and large hose.
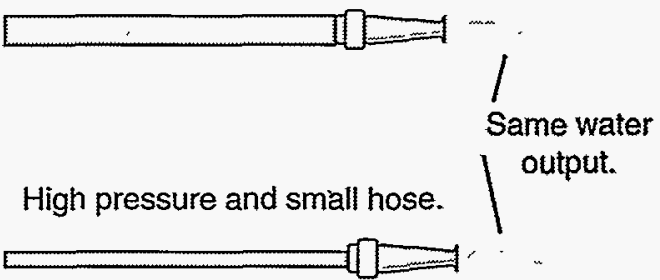

Good conductor: open hose.

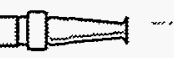

Poor conductor: kìnked hose.

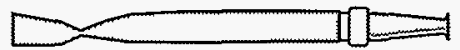


homes. Distribution lines operate at voltages such as $25 \mathrm{kV}$ and $12 \mathrm{kV}$. These levels are further reduced to $120 / 240 \mathrm{~V}$ when the power gets to homes and businesses.

Electrical substations serve many functions in controlling and transferring power on an electrical system. Several different types of equipment may be present, depending on the functions of the particular substation. For example, transformers change the high voltages used by transmission lines to the lower voltages used by distribution lines. Circuit breakers are used to turn lines on and off. The figure below shows how these facilities fit together in an electric power system.

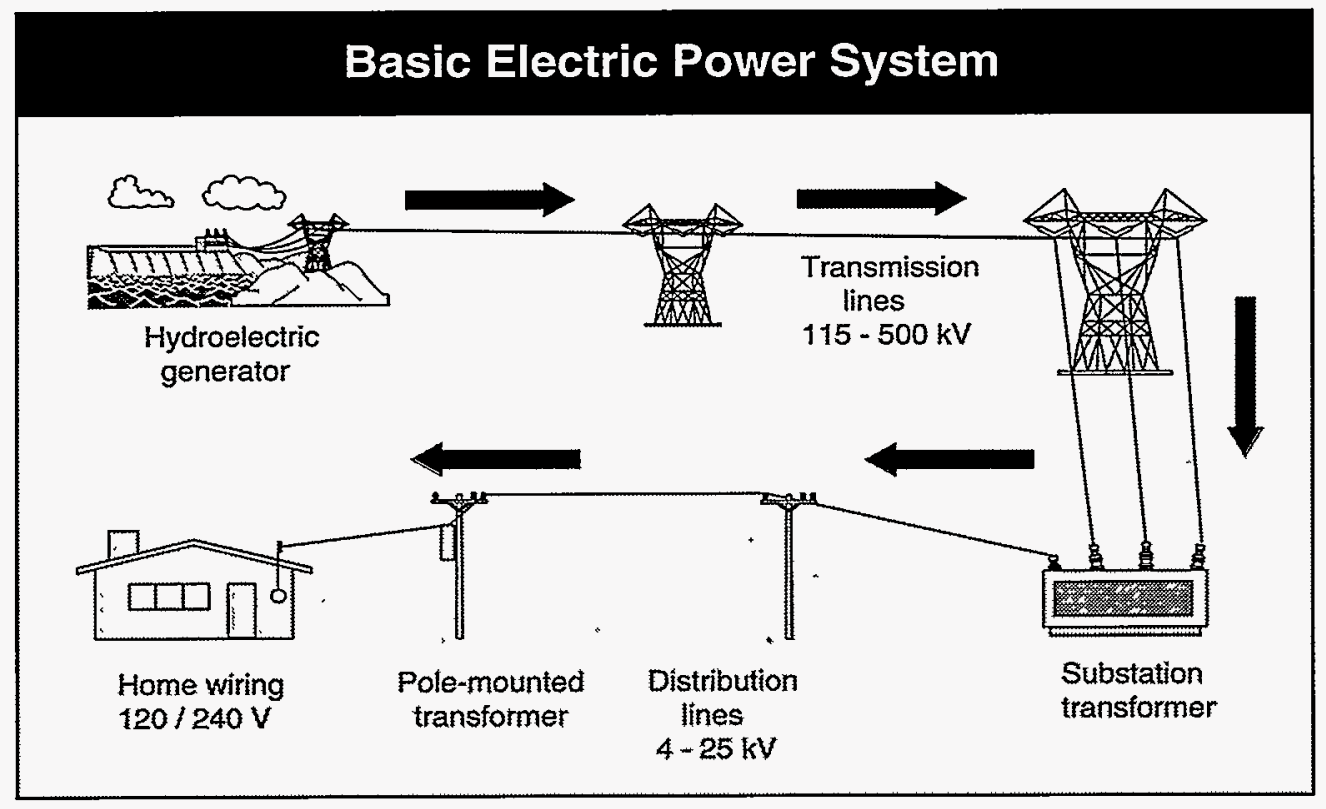

4 


\section{QUESTIONS AND ANSWERS}

\section{Q What are electric and magnetic fields (EMF)?}

DC magnetic field around a bar magnet.

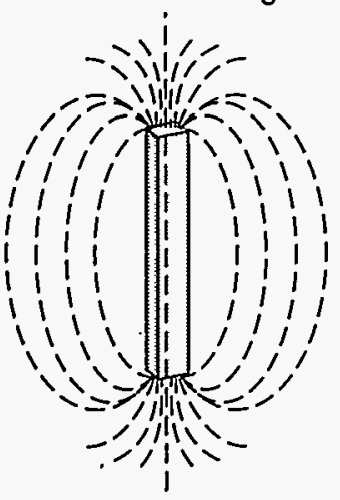

A Power lines, electrical wiring, and appliances all produce $\mathrm{AC}$ electric and magnetic fields. EMF are invisible lines of force that exist in the area surrounding any electrical device. The DC magnetic field from a magnet (left) can be shown by sprinkling iron filings around a magnet placed on a sheet of paper. Electric and magnetic fields have different properties, and possibly different ways of causing biological effects. Therefore, at times it is useful to talk about the two fields separately. The two fields are compared below.

\begin{tabular}{|c|c|}
\hline Electric Fields & Magnetic Fields \\
\hline $\begin{array}{l}\text { 1. Produced by voltage. } \\
\begin{array}{l}\text { Lamp plugged in } \\
\text { but turned off. } \\
\text { Voltage produces } \\
\text { an electric field. }\end{array}\end{array}$ & $\begin{array}{l}\text { 1. Produced by current } \\
\text { Lamp plugged in and } \\
\text { turned on. Current } \\
\text { now produces a } \\
\text { magnetic field, also. }\end{array}$ \\
\hline $\begin{array}{l}\text { 2. Measured in volts per meter }(\mathrm{V} / \mathrm{m}) \text { or in } \\
\text { kilovolts per meter }(\mathrm{kV} / \mathrm{m}) \text {. } \\
1 \mathrm{kV}=1000 \mathrm{~V}\end{array}$ & $\begin{array}{l}\text { 2. Measured in gauss }(G) \text { or tesla }(T) \\
1 \text { milligauss }(\mathrm{mG})=0.1 \text { microtesla }(\mu \mathrm{T}) \\
\text { milli }(\mathrm{m})=1 \text { thousandth } \\
\text { micro }(\mu)=1 \text { millionth }\end{array}$ \\
\hline $\begin{array}{l}\text { 3. Easily shielded (weakened) by conducting } \\
\text { objects like trees and buildings. }\end{array}$ & $\begin{array}{l}\text { 3. Not easily shielded (weakened) by } \\
\text { most material: }\end{array}$ \\
\hline $\begin{array}{l}\text { 4. Reduced in strength with increasing } \\
\text { distance from the source. }\end{array}$ & $\begin{array}{l}\text { 4. Reduced in strength with increasing } \\
\text { distance from the source. }\end{array}$ \\
\hline
\end{tabular}


Q How do electric power EMF compare to other types of fields?

A The electromagnetic spectrum (right) covers an enormous range of frequencies which are expressed in Hertz ( $\mathrm{Hz}$ ) (cycles per second). Electric power ( $60 \mathrm{~Hz}$ in North America, $50 \mathrm{~Hz}$ elsewhere) is in the extremely-low-frequency (ELF) range. ELF includes frequencies below $3,000 \mathrm{~Hz}$.

In general, the higher the frequency, the greater the amount of energy in the field. Microwave frequency fields can have enough energy to cause heating in conducting material. Still higher frequencies like X-rays cause ionization: breaking of molecular bonds that damages genetic material. In comparison, ELF fields have very low energy levels which do not cause heating or ionization. However, AC fields, including those in the ELF range, do create weak electric currents in conducting objects, including people and animals (see page 15).

\section{Some points about the figure on the right:}

Frequency is shown in $\mathrm{Hertz}(\mathrm{Hz}) .1 \mathrm{~Hz}=1$ cycle per second. (Note that $10^{4}$ means $10 \times 10 \times 10 \times 10=10,000 \mathrm{~Hz}$, etc.) $\mathrm{kHz}=$ kilohertz $=1,000 \mathrm{~Hz}, \mathrm{MHz}=$ megahertz $=$ million $\mathrm{Hz}$

As frequency goes up, wavelength gets shorter, and more energy is transferred to objects similar in size to the wavelength.

Examples:

\section{Source}

Power line

Frequency $60 \mathrm{~Hz}$

Microwave oven

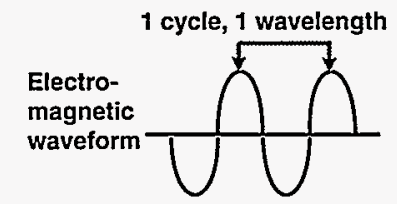

Wavelength $5,000 \mathrm{~km}(3,100$ miles $)$ $12.2 \mathrm{~cm}(4.8 \mathrm{in}$.

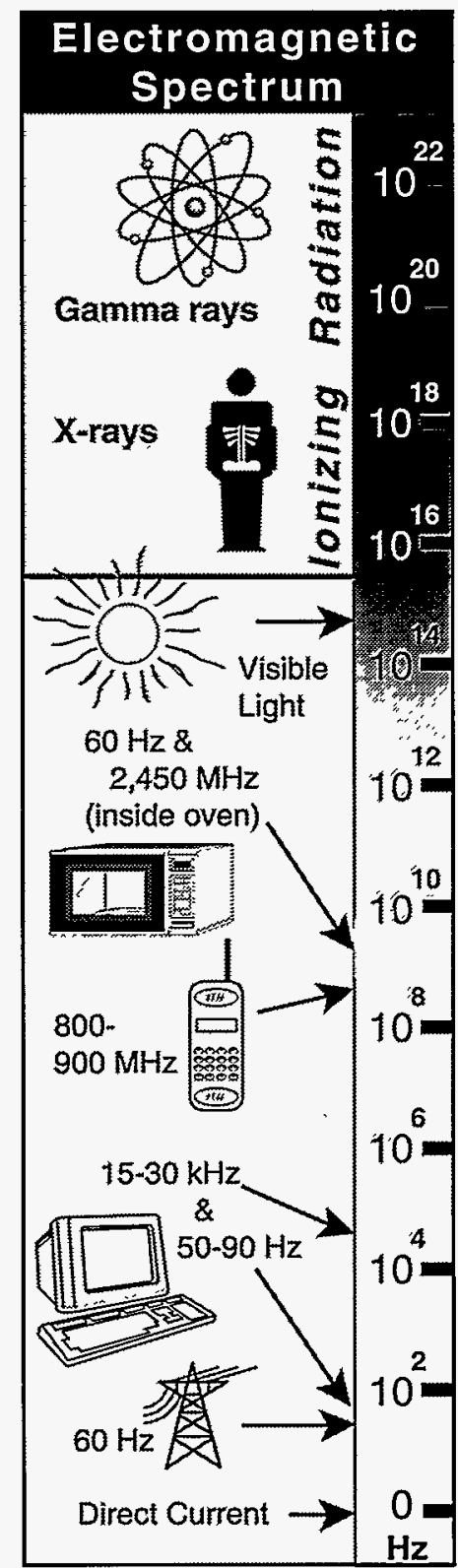


Earth's DC electric field comes from thunderstorms.

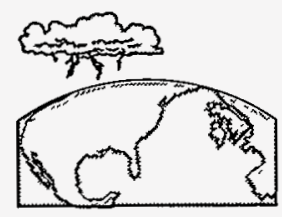

Earth's DC magnetic field comes from currents in the earth.

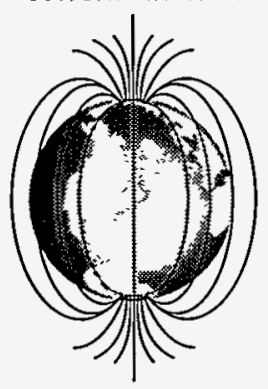

Q Doesn't the earth produce EMF?

A Yes, the earth produces EMF which are mainly DC (also called static fields). Electric fields are produced by thunderstorm activity in the atmosphere. Near the ground, the DC electric field averages less than $200 \mathrm{~V} / \mathrm{m}$. Much stronger fields occur directly beneath electrical storms.

Magnetic fields are thought to be produced by electric currents flowing deep in the earth. The earth acts like a large magnet. The DC magnetic field averages around $500 \mathrm{mG}$. This number is larger than typical AC electric power magnetic fields, but DC fields do not create currents in objects in the way that $\mathrm{AC}$ fields do (see page 15).

Q How do EMF from transmission lines and appliances compare?

A Electric fields close to transmission lines are much stronger than the fields found near electrical appliances. However, remember that electric fields are reduced in strength greatly by objects like buildings, trees, and vehicles. Magnetic fields very close to electrical appliances are often stronger than the fields directly beneath power lines. However, appliance fields decrease in strength with distance more quickly than do power line fields (page 8).

Some appliances also produce both $60-\mathrm{Hz}$ and higher-frequency fields. For example, video displays such as TV sets and video display terminals 
(VDTs) used with computers produce radio-frequency fields (10-30 kHz) as well as ELF fields. Typical 60-Hz magnetic fields for some appliances are shown in the box below. Appliance electric fields are usually less than $100 \mathrm{~V} / \mathrm{m}$ at $30 \mathrm{~cm}(1 \mathrm{ft}$.) from the appliance. Some typical EMF levels for transmission lines are shown on page 9.

\section{0-Hz Magnetic Fields for Some Appliances}

Magnetic Fields Measured At Two Distances From Appliances on the Left

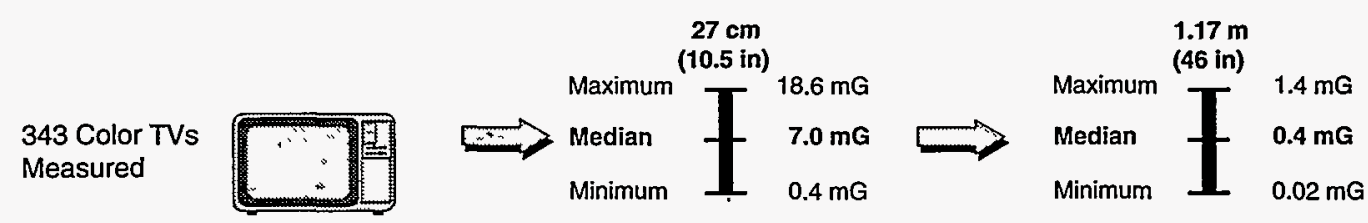

383 Electric Ranges Measured
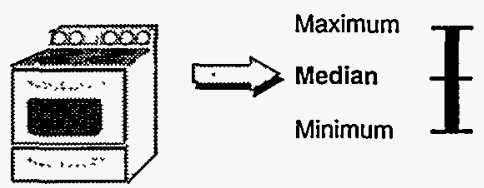

$28.6 \mathrm{mG}$

$9.0 \mathrm{mG}$

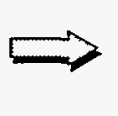

$\left.\begin{array}{l}\text { Maximum } \\ \text { Median } \\ \text { Minimum }\end{array}\right] \begin{aligned} & 6.2 \mathrm{mG} \\ & 0.3 \mathrm{mG} \\ & 0.0 \mathrm{mG}\end{aligned}$

485 Microwave

Ovens Measured

(Outside 60-Hz field,
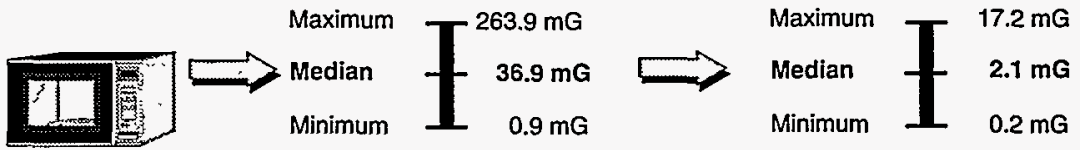

not inside the oven)

118 Analog Clocks Measured
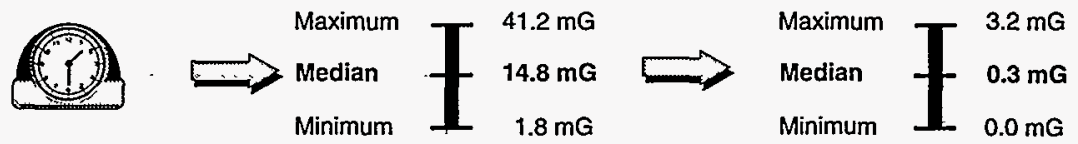

SOURCE: Zaffanella 1993

8 


\section{Typical EMF Levels for Transmission Lines *}

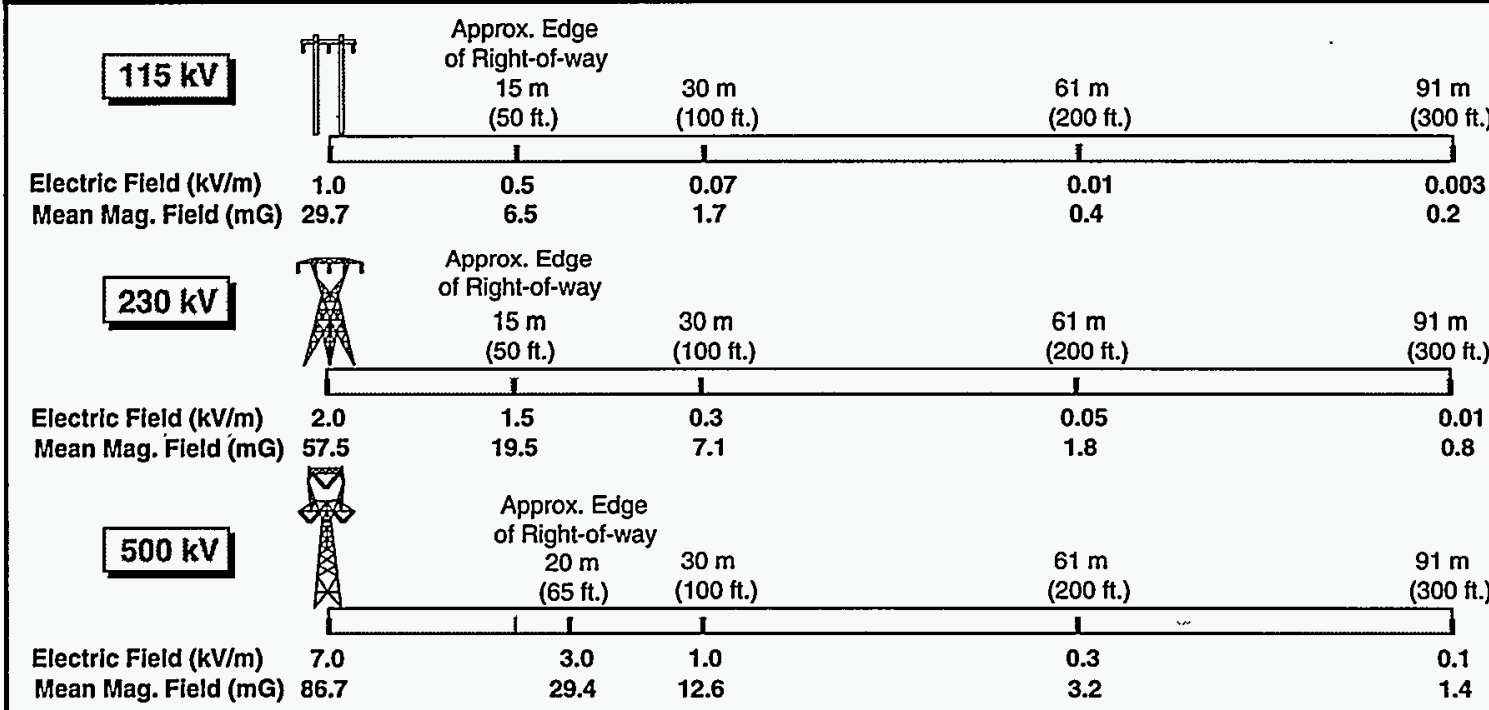

Magnetic Field From a 500-kV Transmission

Line Measured on the Right-of-way Every 5 Minutes for 1 Week

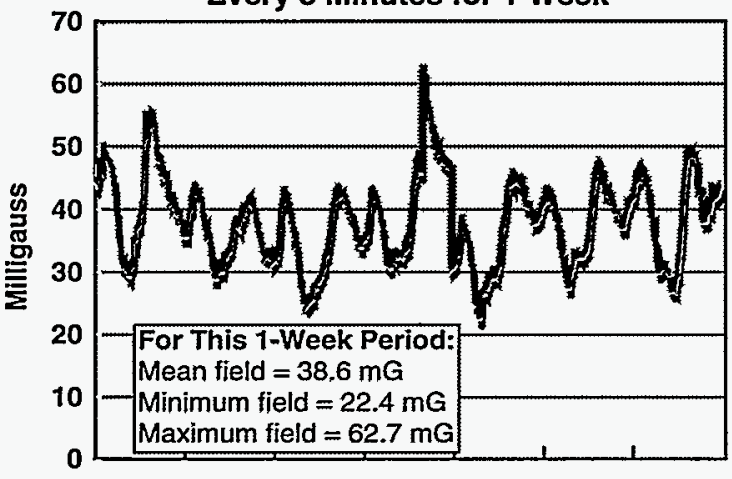

Thur Fri Sat Sun Mon Tue Wed Thu
Electric fields from power lines are relatively stable because line voltage doesn't change very much. Magnetic fields on most lines fluctuate greatly as current changes in response to changing loads. Magnetic fields must be described statistically in terms of averages, maximums, etc. The magnetic fields above are means calculated for 321 BPA lines for 1990 annual mean loads. During peak loads (about $1 \%$ of the time) magnetic fields are about twice as strong as the mean levels above. The graph on the left is an example of how the magnetic field varied during 1 week for one 500-kV transmission line.

* These are typical EMF at $1 \mathrm{~m}$ (3.3 ft.) above ground for various distances from BPA lines. They are for general information. For information about a specific BPA line, see page 33. For other lines, contact the utility that operates the line. 


\title{
Q How strong are the EMF from electric power substations?
}

A In general, the strongest EMF around the outside of a substation come from the power lines entering and leaving the station. The equipment within the station typically does not produce large EMF beyond the substation fence. The strength of the EMF from transformers decreases rapidly with increasing distance, in a way similar to that of household electrical appliances.

\section{Q What are some typical EMF exposures?}

A First, "exposure" must be defined. Scientists are still uncertain about the best way to do this. One problem is that we are usually exposed to EMF from a large number of sources every day. Should exposure be an average of the time spent in these fields, or is it important to know how much time we spend in high fields above certain levels?

Several kinds of small meters are now available that can be carried or worn by a person to record magnetic field exposures automatically. The figure on page 11 is an example of data collected with one of these meters. It shows the magnetic field measured every 24 seconds over a 24 -hour period. For this person, field exposure at home was very low. The occasional spikes (short exposures to high fields) occurred when the person drove or walked under power lines, or was close to appliances in the home or office.

The strength of the EMF from electric transformers weakens rapidly with distance, as it does from electrical appliances.

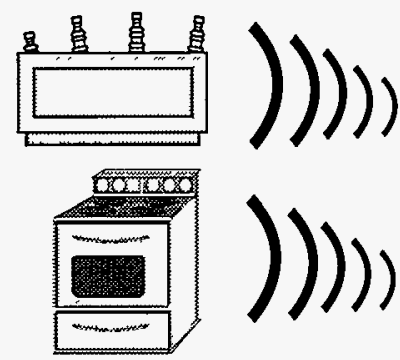

\begin{abstract}
"AVERAGES"
There are two common ways of describing a middle value in a sample of measurements: Mean $=$ The sum of all measurements in a sample divided by the : number of measurements. Median = The middle measurement in a sample arranged in order of size. There are as many measurements larger than the median as there are smaller. The median is useful for data with some very high or very low measurements.
\end{abstract}


The figure below is a random sample of the magnetic field exposure of a BPA employee over a 24 -hour period. This person works in an office with a computer, and lives in an allelectric house by a "very low current configuration" power line (see page 12).
Some studies have used these automatic gaussmeters to measure human exposure to magnetic fields (see page 12). These studies tend to show that appliances and building wiring contribute to the low-level background magnetic field exposure that most people receive. People living close to large power lines tend to have higher overall field exposures. However, as shown on page 12 , there is much individual variation among homes.

\section{Example of 24-Hour Magnetic Field Exposure}

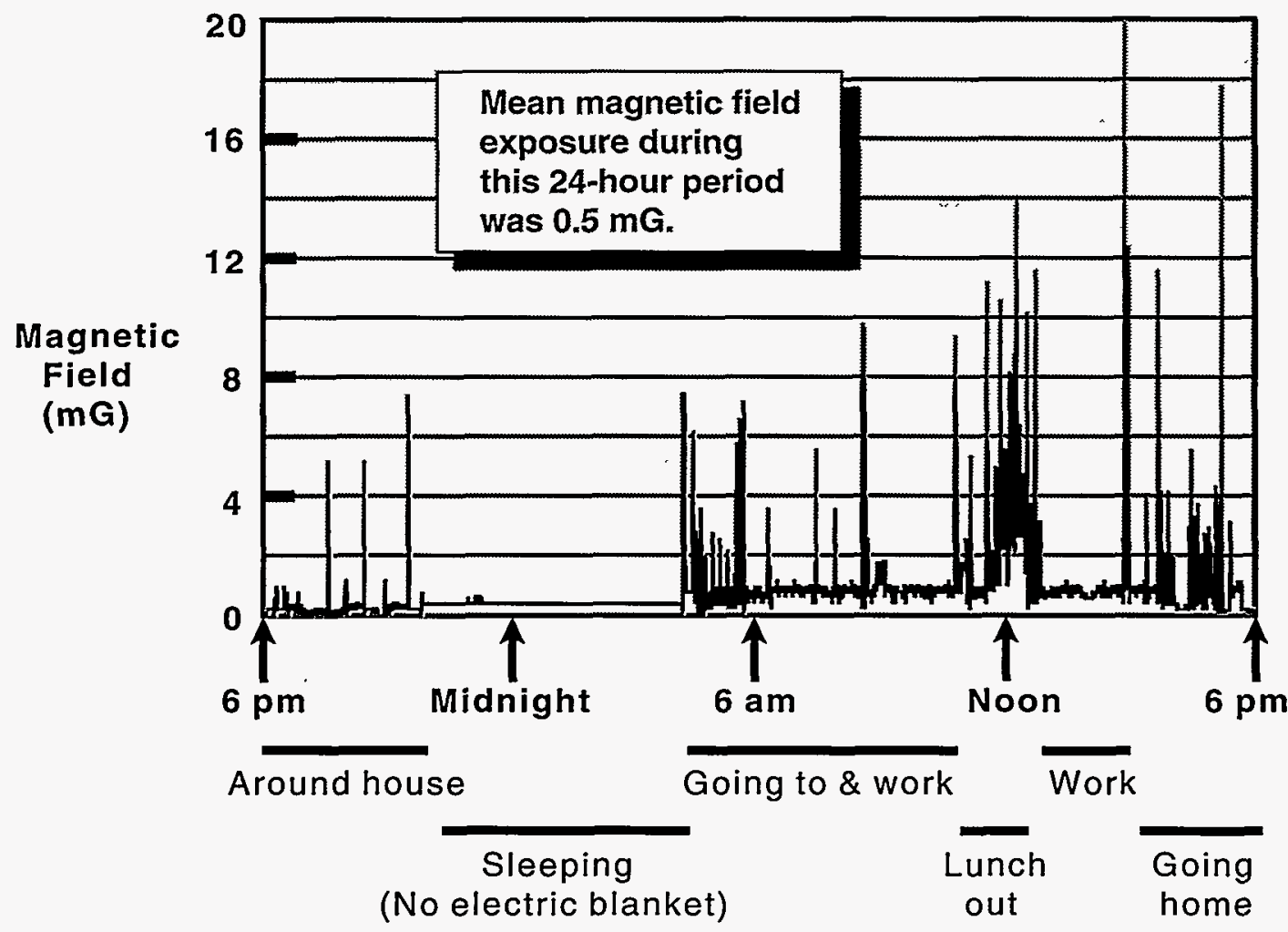




\section{Magnetic Field Exposures Measured by Gaussmeters Worn by People Living Near Various Types of Power Lines}

The five categories below were used to estimate magnetic field exposures in some studies of cancer in people living near power lines (see page 17).

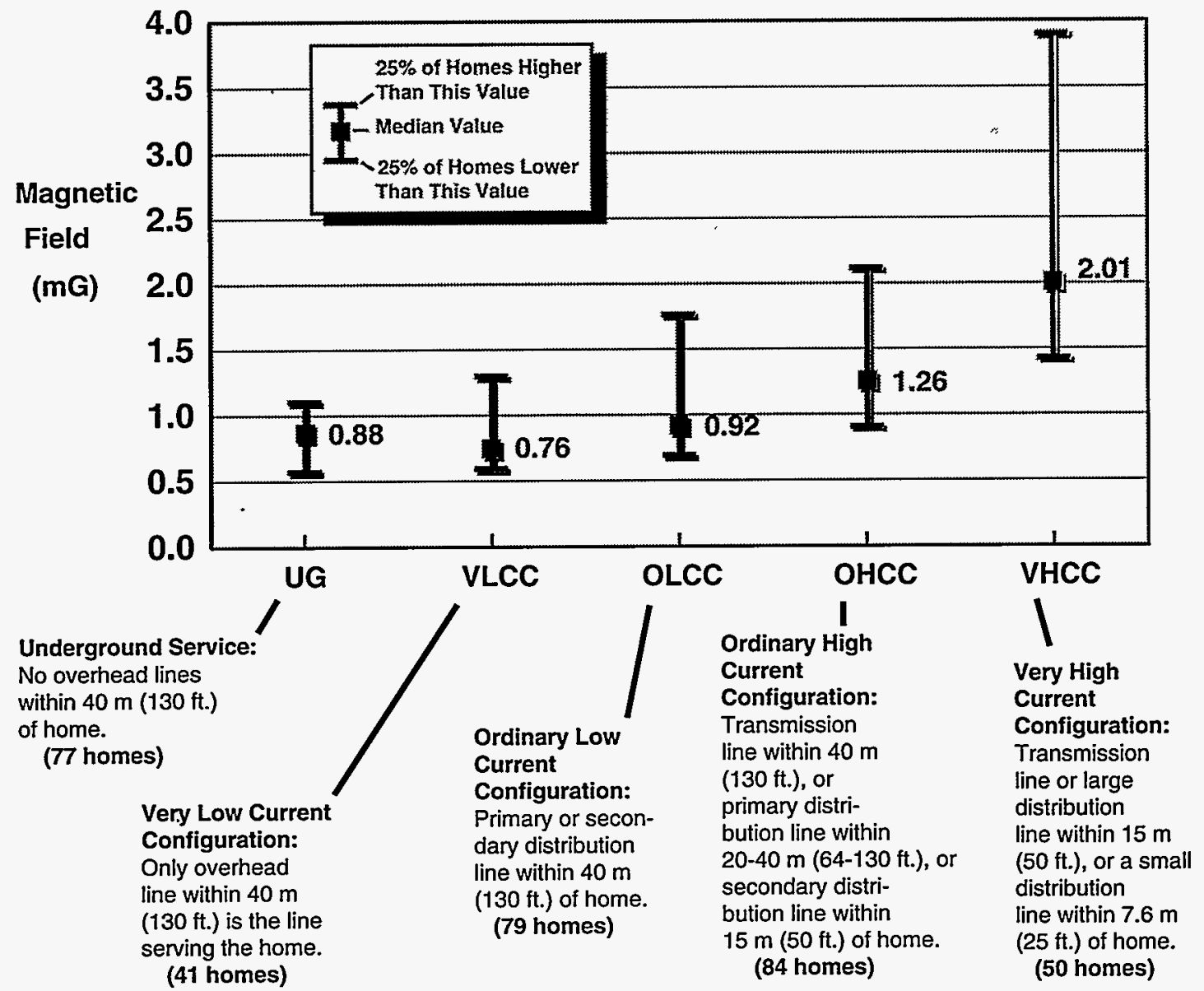

SOURCE: Bracken 1994 


\section{Q Are there any standards for $60-\mathrm{Hz}$ EMF?}

A In the U.S., there are no Federal health standards specifically for $60-\mathrm{Hz}$ EMF. A professional society, the American Conference of Governmental Industrial Hygienists (ACGIH), has developed "Threshold Limit Values" for EMF which include $60 \mathrm{~Hz}$ (below). These are guidelines for use by industrial hygienists in occupational settings. They are not a line between safe and unsafe EMF levels.

\section{Occupational Threshold Limit Values for 60-Hz EMF (ACGIH)}

Electric Field

Occupational exposures should not exceed:

$25 \mathrm{kV} / \mathrm{m}$ (from $0 \mathrm{~Hz}$ to $100 \mathrm{~Hz}$ ).

Prudence dictates the use of protective devices (e.g. suits, gloves, insulation) in fields above $15 \mathrm{kV} / \mathrm{m}$.

For workers with cardiac pacemakers: Maintain exposure at or below $1 \mathrm{kV} / \mathrm{m}$.

\section{Magnetic Field}

Routine occupational exposure should not exceed:

$10 \mathrm{G}(10,000 \mathrm{mG})$.

For workers with cardiac pacemakers, the field should not exceed:

$$
1 \mathrm{G}(1,000 \mathrm{mG}) \text {. }
$$

At least six states have set standards for transmission line electric fields; two of these also have standards for magnetic fields (see page 14). The two state magnetic field standards (New York and Florida) are basically the maximum fields that existing lines in those states produce under maximum load-carrying conditions. Interim guidelines on limits of exposure to $50 / 60-\mathrm{Hz}$ EMF have been developed by the International Commission on Non-Ionizing Radiation Protection. These limits

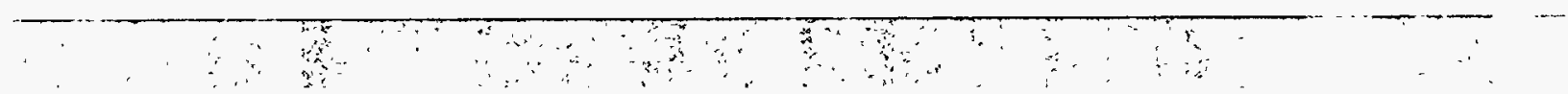


are based on established effects of EMF (e.g., nerve stimulation) and they are much higher than EMF levels found typically in occupational and residential environments (see table below).

\begin{tabular}{|c|c|c|c|c|}
\hline \multirow[t]{2}{*}{ State } & \multicolumn{2}{|c|}{ Electric Field } & \multicolumn{2}{|c|}{ Magnetic Field } \\
\hline & On R.O.W. & Edge R.O.W. & On R.O.w. & Edge R.O.W. \\
\hline Florida & $\begin{array}{r}8 \mathrm{kV} / \mathrm{m} \\
10 \mathrm{kV} / \mathrm{m}\end{array}$ & $2 \mathrm{kV} / \mathrm{m}$ & - & $\begin{array}{l}150 \mathrm{mG}^{\mathrm{a}} \text { (max. load) } \\
200 \mathrm{mG}^{\mathrm{b}} \text { (max. load) } \\
250 \mathrm{mG}^{\mathrm{c}} \text { (max. load) }\end{array}$ \\
\hline Minnesota & $8 \mathrm{kV} / \mathrm{m}$ & -.. & -- & -- \\
\hline Montana & $7 \mathrm{kV} / \mathrm{m}$ & $1 \mathrm{kV} / \mathrm{m}$ & $-\cdots$ & --- \\
\hline New Jersey & - & $3 \mathrm{kV} / \mathrm{m}$ & -- & - \\
\hline New York & $\begin{array}{l}11.8 \mathrm{kV} / \mathrm{m} \\
11 \mathrm{kV} / \mathrm{m} \\
7 \mathrm{kV} / \mathrm{m}\end{array}$ & $1.6 \mathrm{kV} / \mathrm{m}$ & -- & $200 \mathrm{mG}$ (max. load) \\
\hline Oregon & $9 \mathrm{kV} / \mathrm{m}$ & $\cdots$ & - & -- \\
\hline $\begin{array}{l}{ }^{a} \text { For } \\
{ }^{b} \text { For } \\
{ }_{\text {For }}\end{array}$ & $\begin{array}{l}69 \text { to } 230 \mathrm{kV} \\
\text { lines } \\
\text { lines on certai }\end{array}$ & isting R.O.W. & $\begin{array}{l}\text { kimum for high } \\
\text { simum for priva } \\
W=\text { Right-of- }\end{array}$ & $\begin{array}{l}\text { lay crossings } \\
\text { e road crossings } \\
\text { vay }\end{array}$ \\
\hline
\end{tabular}

\section{International Commission on Non-lonizing Radiation Protection}

\begin{tabular}{|c|c|c|}
\hline Exposure $(50 / 60 \mathrm{~Hz})$ & Electric Field & Magnetic Field \\
\hline $\begin{array}{l}\text { Occupational: } \\
\text { Whole working day } \\
\text { Short term }{ }^{a} \\
\text { For limbs } \\
\text { General Public: } \\
\text { Up to } 24 \text { hours per day } \\
\text { Few hours per day }\end{array}$ & $\begin{array}{r}10 \mathrm{kV} / \mathrm{m} \\
30 \mathrm{kV} / \mathrm{m} \\
\\
5 \mathrm{kV} / \mathrm{m} \\
10 \mathrm{kV} / \mathrm{m}\end{array}$ & $\begin{array}{rr}5 \mathrm{G} & (5,000 \mathrm{mG}) \\
50 \mathrm{G} & (50,000 \mathrm{mG}) \\
250 \mathrm{G} & (250,000 \mathrm{mG}) \\
1 \mathrm{G} \quad(1,000 \mathrm{mG}) \\
10 \mathrm{G}(10,000 \mathrm{mG})\end{array}$ \\
\hline $\begin{array}{l}\text { For electric fields of } 10-30 \mathrm{kV} / \mathrm{m} \text {, fit } \\
\text { whole working day. Whole-body ex }\end{array}$ & $\begin{array}{l}x \text { hours of } \\
c \text { fields up to }\end{array}$ & $\begin{array}{l}\text { Source: } \\
\text { IRPA/INIRC 1990 }\end{array}$ \\
\hline
\end{tabular}




\section{Q What happens when I am exposed to EMF?}

A person standing in an electric field (blue lines) showing induced current (white dashed lines).

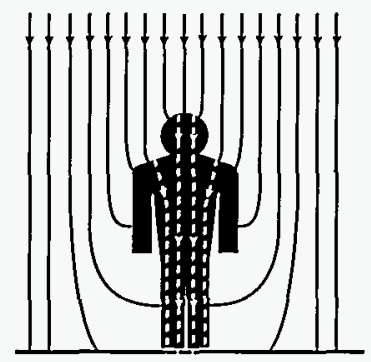

A person standing in a magnetic field (blue lines) showing induced current (white dashed lines).

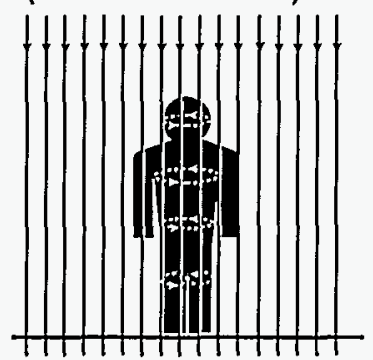

Most of the $60-\mathrm{Hz}$ current occurs between the cells.

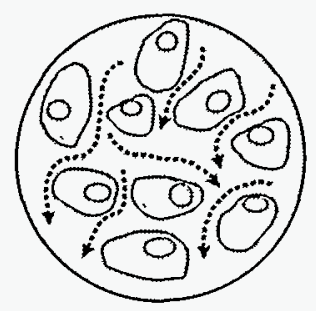

A AC fields create weak electric currents in the bodies of people and animals. This is one reason why there is a potential for EMF to cause biological effects. As shown on the left, currents from electric and magnetic fields are distributed differently within the body. The amount of this current, even if you are beneath a large transmission line, is extremely small: millionths of an ampere. The current is too weak to penetrate cell membranes, so the current is present mostly between the cells.

Currents from $60-\mathrm{Hz}$ EMF are weaker than natural currents in the body - such as those from the electrical activity of the brain and heart. Some scientists argue that it is, therefore, impossible for EMF to have any important effects. Other scientists point to results of some studies which show that biological effects can be caused by exposure to EMF (see page 27). In most cases, however, it is not clear how EMF actually produce these demonstrated effects. .

Strong electric fields, such as those found beneath large transmission lines, can also cause hair on your exposed head or arms to vibrate at $60 \mathrm{~Hz}$. This is felt by some people as a tingling sensation. EMF from transmission lines can also cause nuisance shocks from voltages created by EMF on objects like metal fences (see page 37). 


\section{Q How do scientists study possible effects of power lines on people?}

A They use a type of research called epidemiology. Epidemiology is the study of patterns and possible causes of diseases in human populations. Epidemiologists study short-term epidemics such as outbreaks of food-poisoning, and long-term diseases such as cancer and heart disease. Results of these studies are reported in terms of statistical associations between various factors and disease. The

Epidemiologists want to find out whether some factor may be a cause of a particular disease. They often conduct case-control studies to help answer their questions. The basic steps in a case-control study are summarized in the table below.

\section{How Epidemiologists Conduct Case-Control Studies}

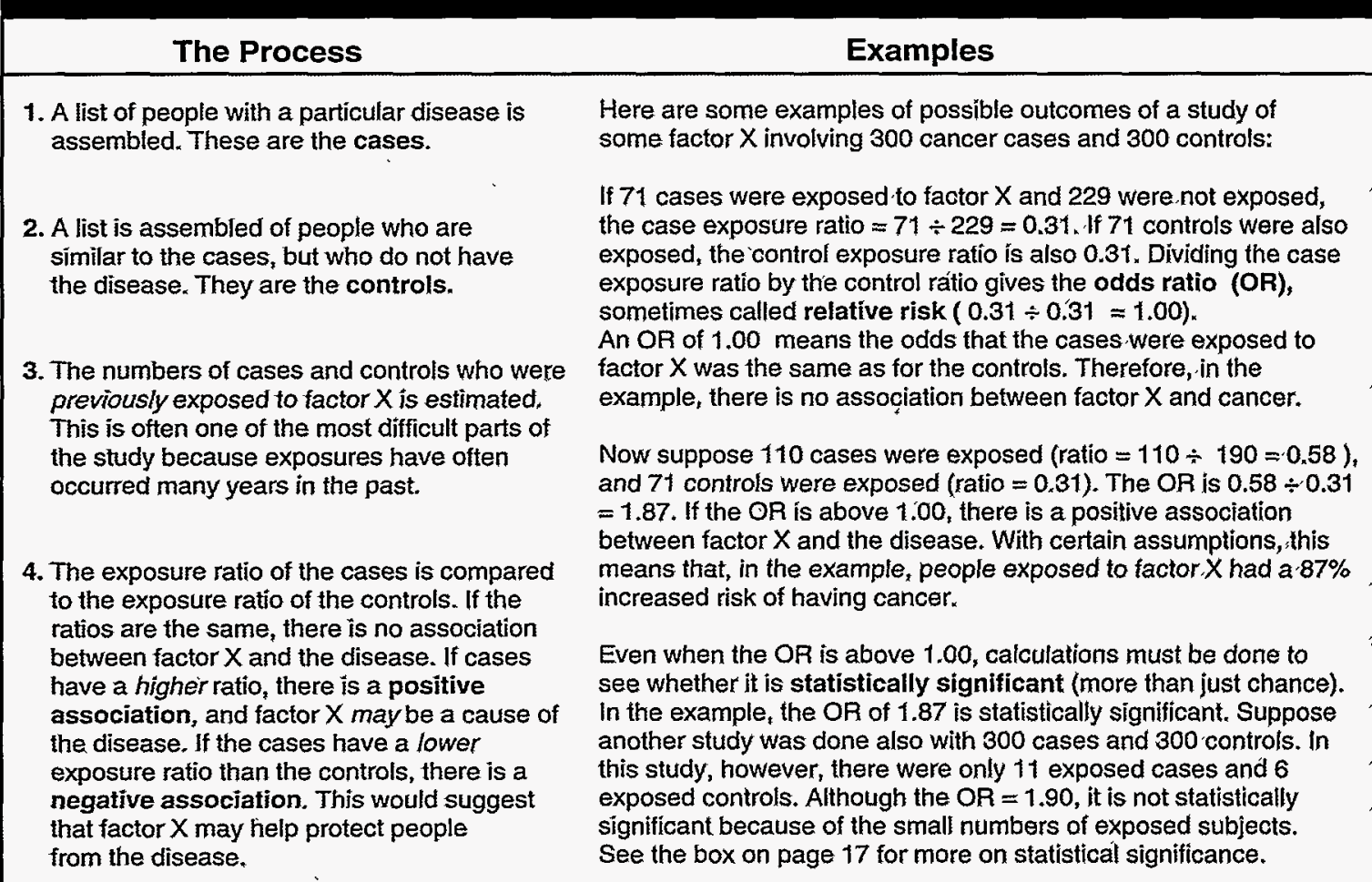


To estimâte sampling variability, $.95 \%$ confidence intervals are calculated. For positive associations, a risk is statistically significant if the lower limit of the interval is greater than unity, e.g., $>1.00$. The box below shows how small numbers of exposed subjects can result in wide confidence intervals, and nonsignificant results. challenge is to discover whether the results indicate a true causal association. This includes assessing possible effects of other factors (confounders) that could affect study results. A statistically significant finding does not necessarily mean a cause-effect association. Usually, supplemental data are needed from studies of laboratory animals before scientists conclude that some factor is a cause of a disease.

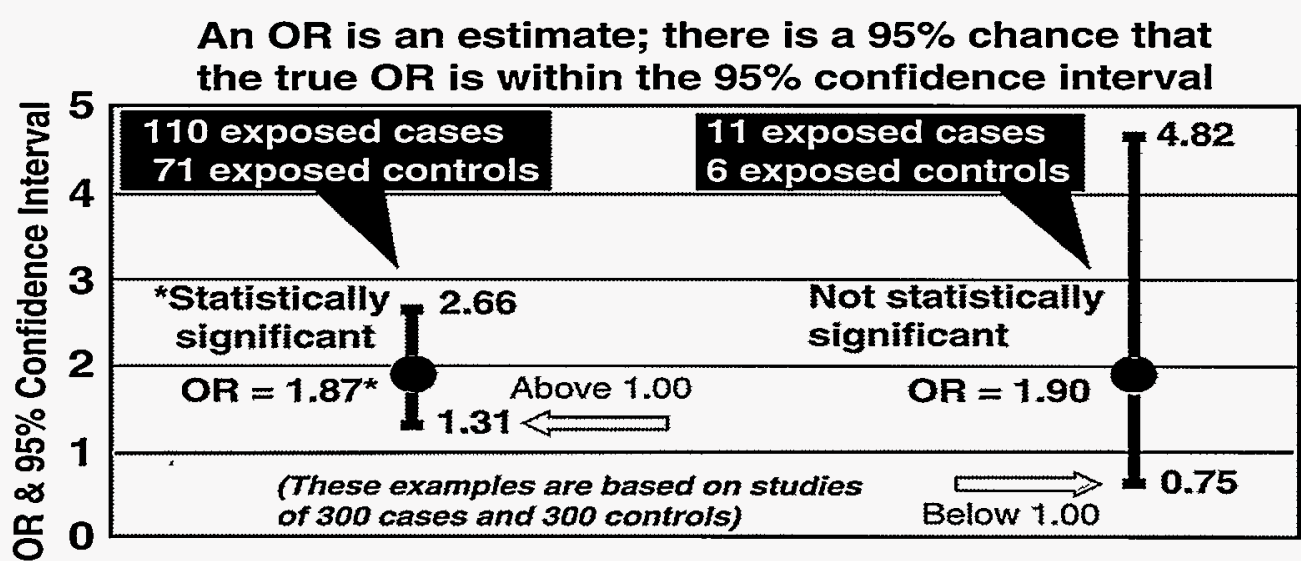

A 1979 study in Denver by Wertheimer and Leeper first reported that children who developed cancer were more likely to have lived within about $15-40 \mathrm{~m}$ (49-131 ft.) of high-current distribution lines.

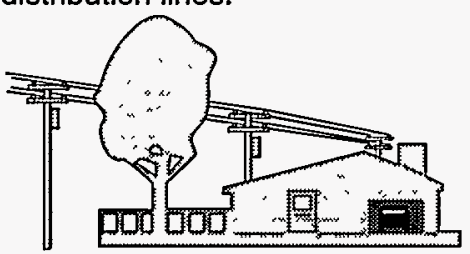

Q What have the studies of cancer in people living near power lines found?

A Several studies have reported positive associations between cancer and power lines (see page 18), but a causal association has not been established. The first study to report an association between power lines and cancer was done in Denver in the late 1970s. The study found that children who had died from cancer were two to three times more likely to have lived near high-current distribution lines compared to children who did not have cancer. 


\section{Summary of Residential Power-Line Cancer Studies}

\section{Study Location Leukemia Other Cancers}

Child Cancer Studies-

\begin{tabular}{|c|c|c|c|}
\hline Wertheimer \& Leeper' 79 & Denver, CO & $\mathrm{OR}=2.35^{*}$ & All Cancer OR $=2.22^{*}$ \\
\hline Fulton et al. ' 80 & Rhode Island & $\mathrm{OR}=1.09$ & Not Studied \\
\hline Tomenius ${ }^{\prime} 86$ & Sweden & $O R=0.30$ & CNS Tumors OR $=3.70^{*}$ \\
\hline Savitz et al. '88 & Denver, $\mathrm{CO}$ & $O R=1.54$ & Afl Cancer OR $=1.53^{*}$ \\
\hline Coleman et al. :89 & U.K. & $O R=1.50$ & Nol Studied \\
\hline Lin \& Lu '89 & Taiwan & $O R=1.31$ & All Cancer $O R=1.30$ \\
\hline Myers et al. '90 & U.K. & $O R=1.14 t$ & All Cancer OR $=0.98$ \\
\hline London et al. '91 & Los Angeles, CA & $O R=2.15^{\star}$ & Not Studied \\
\hline Lowenthal et al. '91 & Australia & $O / E=2.00$ & \\
\hline Feychting \& Ahlbom '93 & Sweden & $\mathrm{OR}=3.80^{*}$ & All Cancer OR $=1.30$ \\
\hline Olsen et al. '93 & Denmark & $O R=1.50$ & All Cancer OR $=5.60^{*}$ \\
\hline Petridou et al. 93 & Greece & $O R=1.19$ & Nol Studied \\
\hline Verkasalo'93 & Finland & $\operatorname{SIR}=1.60$ & $\begin{array}{l}\text { All Cancer SIR }=1.50 \text {, } \\
\text { CNS Tumors in Boys, } \operatorname{SIR}=4.20^{*}\end{array}$ \\
\hline Fajardo-Gutiérrez et al. '93 & Mexico & $O A=2.63^{*}$ & Not Studied \\
\hline
\end{tabular}

Adult Cancer Studies

Wertheimer \& Leeper '82 McDowall ' 86

Severson et al. ' 88

Coleman et al. ' 89

Youngson et al. ' 91

Eriksson \& Karlsson '92

Feychting \& Ahlbom '92

Schreiber et al. '93
Denver, $\mathrm{CO}$
U.K.
Seattle, WA
U.K.
U.K.
Sweden
Sweden
The Netherlands
$O R=1.00$
$S M R=143$
$\mathrm{OR}=0.80$
All Cancer $O R=1.28$
$\mathrm{OR}=0.90$
Not Siudied
Leukemia \& Lymphoma $\mathrm{OR}=1.29$
Not studied Multiple Myeloma $\mathrm{OR}=0.94$
$\mathrm{OR}=1.00 \quad$ (Leukemia Subtypes $\mathrm{OR}=1.70$ )
No Cases
All Cancer $\mathrm{SMR}=85$,
Hodgkins Disease SMR $=469$

Notes: $\quad$ This table is intended to summarize briefly some of the selected, often-cited results of the residential cancer studies. The full papers should be consulted for details (see References section).

Abbreviations:

OR = Odds Ratio (see page 16). An OR of 1.00 means no increased or decreased risk.

SMR = Standardized Mortality Ratio. An SMR of 100 means no increased or decreased risk.

SIR = Standardized Incidence Ratio. An SIR of 1.00 means no increased or decreased risk.

CNS $=$ Central nervous system

$\mathrm{O} / \mathrm{E}=$ Observed number of cases divided by the expected number of cases.

* This means that the number is statistically significant (greater than expected by chance), page 17.

† For nonsolid tumors, which includes leukemias and lymphomas. 
Child Cancer Rates

For children in the U.S. under age 15, about 14 out

*. of 100,000 develops some type, of cancer each year from all causes. About onethird of these cases are leukemias. During 1994, it is estimated that there, will be, about 8,200 new cases of child cancer in the U.S., and about 1,600 , deaths. (Sources: National Cancer Institute 1992, American Cancer Society, 1994),
Exposure to magnetic fields was identified as a possible factor in this finding. Magnetic fields were not measured in the homes. Instead, the researchers devised a substitute method to estimate magnetic fields from power lines based on (1) the size and number of power line wires, and (2) distance of power lines from the home (see page 12).

A second study in Denver in 1988, and one in Los Angeles in 1991, also found significant associations between living near high-current-configuration power lines and childhood cancer. However, in these two studies the associations were not significant when measured magnetic fields were used in the analysis. Studies in Sweden, Finland, Denmark, and Mexico, found increased cancer risks for children living near high-voltage transmission lines.

To date, 8 of 14 studies found at least one statistically significant association between various types of childhood cancer and power lines (page 18). Two of eight studies of adults found significant associations between cancer and power lines. Although studies are often characterized this way, the diverse studies can't simply be "added up" in this manner (also, see the margin notes on page 22).

\section{Q What about the Swedish cancer study of people living near transmission lines?}

A In late 1992, researchers in Sweden reported results of a study of cancer in people living near high voltage transmission lines. The Swedish study generated a great deal of interest among scientists, 
the public, and the news media. Relative risk for leukemia increased in Swedish children who lived within $50 \mathrm{~m}$ (164 ft.) of a transmission line. The risk was found also to increase progressively as the calculated average annual $50-\mathrm{Hz}$ magnetic field increased in strength. However, the risks above were based on very small numbers of cases (see summary below). For adults, overall no statistically significant elevated cancer risks were found.

The Swedish researchers concluded that their study provides additional evidence for a possible link between magnetic fields and childhood leukemia. However, differing opinions have been expressed by scientists about the study. For example, some scientists believe that the study is important because it is based on calculated magnetic fields existing around the time the cancers were diagnosed. Others are skeptical because of the small numbers of cancer cases, and because no cancer association was seen with present-day magnetic field levels.

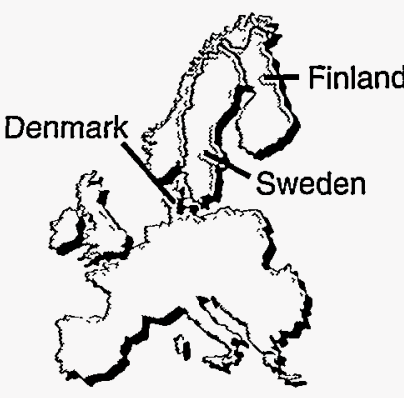

EUROPE

Nordic Studies

Researchers in Sweden, Finland, and Denmark recently combined the results of their transmission line studies. The combined relative risk for child: leukemia was 2.1 and it was statistically significant. This was based, however, on 13 total cases. No significant risks were found for lymphoma or for nervous system tumors. (Ahlbom et al. 1993)

\section{Summary of Swedish Residential Cancer Study}

Cancer cases (from 1960-85) and controls selected from the 500,000 people who had lived on property within $300 \mathrm{~m}$ (984 ft.) of $220-$ and $400-k V$ lines.

- Magnetic field exposure was estimated by: 1) in-home measurements, 2) dwelling distance from lines, and 3) calculated average annual magnetic field before and near time of cancer diagnosis.

The relative risk of child leukemia was 1.50 for calculated fields of 1 to $2.9 \mathrm{mG}$ (based on four leukemia cases), and 3.80 for fields above $3 \mathrm{mG}$ (based on. seven cases). The trend for increasing risk with increasing field strength was statistically significant.
For homes within $50 \mathrm{~m}$ (164 ft.) of transmission lines ( 6 cases) relative risk for child leukemia was 2.90 and it was on the borderline of statistical significance.

Dxcess leukemia risks were confined to one-family homes, and there were no elevated risks for other types of child cancers.

There were no statistically significant elevated cancer risks for adults.

Control for possible effects of air pollution and socioeconomic status did not change study results. SOURCE: Feychting \& Ahlbom 1992,1993 
Cancer cases ( $x$ 's below) in a city may show patterns which appear to be "clusters." They may seem to suggest a common environmental cause. Usually such patterns are just due to chance. Delineation of a cluster is subjective (where do you draw the circles?).

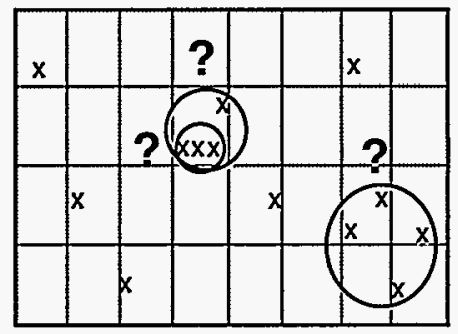

\section{CLUSTERS}

As an analogy, think about how an uncommon family name might be distributed at homes located throughout a city. Would it be : unusual to find neighborhoods where two or three unrelated families with this same last name live in the same 'small area? Statistically, this may be shown to be expected due just to chance. While four or more such 'families may be very unlikely due to chance, this does not mean that it is impossible. One possible cause (other than chance) for some such "name clusters" is that the families are part of the same ethnic group and they choose to live close together. For perceived neighborhood cancer clusters, however, health agencies generally never find a common environmental cause. It is also apparent that the definition of a "cluster" depends on how large an area (neighborhood) is included.
Q Are there high cancer rates in some neighborhoods close to electric power facilities?

A Scientists call unusual occurrences of cancer in an area or in time a "cancer cluster." In some cases, a cancer cluster has served as an early warning of a health hazard. For most reports of cancer clusters, however, the cause is never determined, or the perceived cluster is not really an unusual occurrence.

Concerns have been raised about seemingly high numbers of cancers in some neighborhoods and schools close to electric power facilities. In recent years, three state health departments have studied apparent cancer clusters near electric power facilities. A Connecticut study involved five cases of brain and central nervous system cancers in people living near an electrical substation. The local rates for these types of cancer were found to be no different from state-wide rates. Examination of cancer rates at various distances from the substation also failed to show evidence of clustering. In North Carolina, several cases of brain cancer were identified in part of a county that included an electricpower-generating plant. An investigation showed that brain cancer rates in the county, however, were actually lower than state-wide rates. Among staff at an elementary school near transmission lines in California, 13 cancers of various types were identified. Although this was twice the expected rate, the state investigators concluded that the cancers could have occurred by chance alone. 


\section{Q Do electrical workers have higher risks of} cancer?

A Several studies have reported increased cancer risks for jobs involving work around electrical equipment. To date it is not clear whether these risks are caused by EMF or other factors. A brief report published in 1982 by Milham was one of the first to suggest that electrical workers have an increased risk of leukemia compared to other occupations. The study was based on death certificates from Washington state, and included workers in 10 occupations assumed to have elevated exposure to EMF. About 49 studies have now reported statistically significant increased risks for various types of cancer in occupational groups exposed to EMF (see table below). Relative risk levels in these studies are mostly less than 2.00 , and the possible influence of other factors such as chemicals has not been
Notes about the table below: Study results are presented in very general terms. The studies can't be "added up" this way to reach some conclusion about health effects. This is because many types of studies are included. Also, many studies that reported no significant risks did report elevated risks (above 1.00). The risks were not significant possibly because of small sample sizes. For studies included as significant, some found only one or a few significant risks out of several that were calculated. When a large number of risks is calculated, some can be "significant" due to chance. Also, studies with positive findings may tend to be published more often than negative studies.

\section{Summary of Results by Cancer Type in Studies of Electrical Workers}

\begin{tabular}{|c|c|c|c|}
\hline Cancer Type & Increased Risks & No Significant Increased Risks & Totals* \\
\hline Leukemia & 22 & 23 & 45 \\
\hline Brain Cancer & 13 & 17 & 30 \\
\hline Male Breast Cancer & 3 & 7 & 10 \\
\hline Female Breast Cancer & 1 & 3 & 4 \\
\hline Other Cancers & 18 & 23 & 41 \\
\hline Totals & 57 & 73 & 130 \\
\hline
\end{tabular}




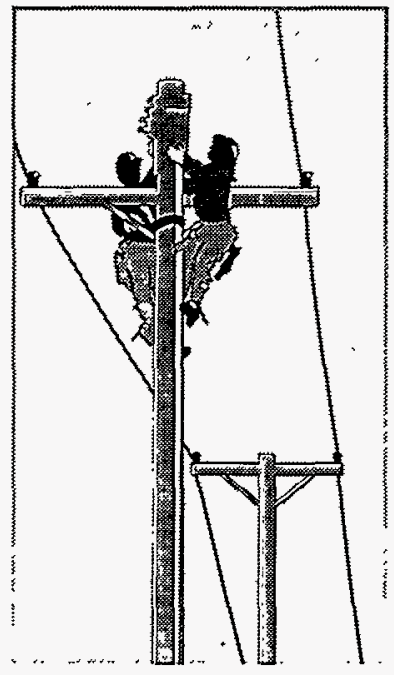

Occupations included in the "electrical" category in the table on the right:

Electrical engineering techs. Electrical engineers.

Electricilans

Power line \& cable workers Power station operators Telephone line workers $T V: \&$ radio repairmen Welders \& flame cutters

Canada-France Study This large study focused on cancer types, associated previously: with magnetic fields including lymphoma, leukemia, brain cancer, and skin melanoma. All other cancers were studied on an exploratory basis. ruled out. At least 30 other studies did not find any significant cancer risks in electrical workers. In most of the studies summarized on page 22, EMF were not measured. Instead, "electrical" job titles were used as indicators of assumed elevated exposure to EMF.

A recent study provided some information on EMF exposures for various electrical workers. As shown in the table below, electrical workers in Los Angeles and Seattle did have higher EMF exposures than non-electrical workers. The Los Angeles electrical workers also had a $29 \%$ increase in leukemia, but there was no association between leukemia and magnetic field exposures among jobs within the group (no "dose-response" trend).

\section{EMF Exposures of Workers in Los Angeles and Seattle}

\begin{tabular}{|l|rr|rc|}
\hline \multicolumn{1}{|c}{ Job Type } & \multicolumn{2}{c}{$\begin{array}{c}\text { Mean Electric Field } \\
\text { Los Angeles }\end{array}$} & \multicolumn{2}{c|}{$\begin{array}{c}\text { Mean Magnetic Field } \\
\text { Los Angeles Seattle }\end{array}$} \\
\hline Electrical & $19.0 \mathrm{~V} / \mathrm{m}$ & $51.2 \mathrm{~V} / \mathrm{m}$ & $9.6 \mathrm{mG}$ & $27.6 \mathrm{mG}$ \\
Non-electrical & $5.5 \mathrm{~V} / \mathrm{m}$ & $10.6 \mathrm{~V} / \mathrm{m}$ & $1.7 \mathrm{mG}$ & $4.1 \mathrm{mG}$ \\
\hline
\end{tabular}

A new study looked at 4,151 cancer cases in over 223,000 workers from two utilities in Canada and one in France. For certain leukemia types, Thériault found statistically significant elevated risks of up to threefold (for cumulative magnetic field exposures above the median). Risk was also elevated significantly (12.3) for one type of brain cancer, but only 
at the highest $10 \%$ level of exposure. There were inconsistencies in results among the three utilities, and no clear indication of a dose-response trend. The authors, therefore, said that their results do not provide definitive evidence that magnetic fields were the cause of the elevated risks found in leukemia and brain cancer. For nearly 30 other types of cancer, no significant elevated risks were found.

\section{Q What have governmental reviews con-} cluded about EMF and cancer?

A Governmental reviews have concluded that existing scientific evidence, although suggestive, does not show that EMF cause cancer. These include national reviews by: an Advisory Board to the U.S. Environmental Protection Agency, Advisory Panel to the Australian Minister of Health, National Radiological Protection Board of the United Kingdom, Danish Ministry of Health, French National Institute of Health and Medical Research, and reviews by the states of California, Texas, Connecticut, Illinois, Maryland, and Colorado.

In 1993 a Swedish agency concluded that, based on results of a recent study in that country (page 19), it is assumed that a causal link exists between magnetic fields and childhood leukemia. The Swedish government is studying cost-benefits of possible magnetic field regulations and other actions that may be adopted. In nearby Denmark, a government agency concluded recently that there was no scientific reason for standards for high-current lines.
A recent electrical worker study in the U.S. involved 36,000 workers at a large utility in California (Sahl et al. 1993). Some elevated risks for leukemia of less than 2.00 were found, but they weren't statistically significant. No consistent evidence of an association between measured magnetic fields and cancer was found in this study.

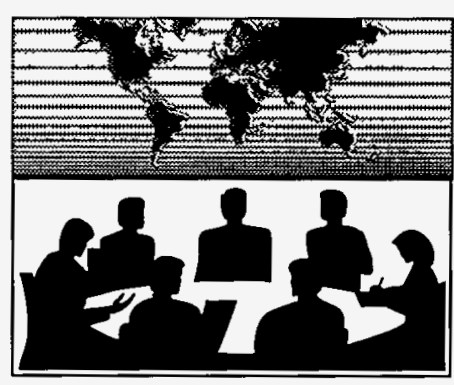

24 


\section{Some Quotes from National EMIF Preirems}

66

... same of the epidemiological evidence is suggestive of an association between surrogate measurements of magnetic-field exposture and certain cancer outcomes... llack of sufficient datal ... prevents the inference of cancer causality from these associations at this time. "9 (U.S. EPA Sclence Advisory Board 1991)

66

... It has not been scientifically established that magnetic fields of extremely low frequency initiate or promote cancer or have any other harmfal effects on humans. However, it has not been scientifically, established that such fields are not harmful.

(Advisory Panel to Australian Minister of Health 1992)

66 ... the epidemiologic findings that have been reviewed provide no firm evidence of the existence of a carcinogenic hazard from exposure [to EMF] ... the findings to date can be regarded only as sufficient to justify formulating a hypothesis for testing by further investigations.

(U.K. National Radiological Protection Board 1992)
66 ... the Danish and Swedish study support the hypothesis of previous studies that chitdren tiving near high-eurrent plants have an increased frequency of cancer But the results do not exclude the possibility that the association might be due to chance. 99

(Danish Ministry of Health 1993)

66

.... the epidemiologic results presently available da not permit the exclusion of a role for magnetic fields in the incidence of leukemia, particularly in children. New investigations are necessary to confirm or deny this role." (French National Institute of Health and Medical Research 1993)•

66

... the Board will act an the assumption that there is a connection between power frequency magnetic fields and childhood cancer, when preparing regulation on electrical installations., ,9

(Swedish National Electric Safety Board 1993)
U.S. per capita electricity sales from 1950-91.

(Kujawa et al. 1992)

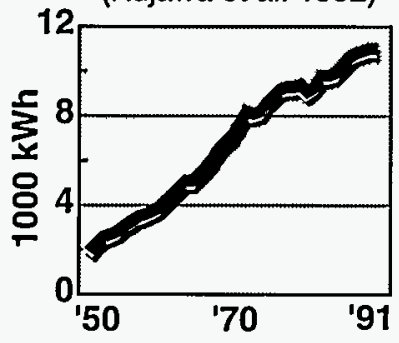

Q If EMF really do cause or promote cancer, shouldn't cancer rates have increased along with the increased use of electricity?

A Not necessarily. Although use of electricity has increased greatly over the years (left), EMF exposures have probably not increased in the same way. Changes in the way that buildings are wired, and in the way electrical appliances are made, have in some cases resulted in lower magnetic field levels. Rates for various types of cancer have shown both increases and decreases through the years. 
For example, mortality rates (deaths) for the two most common cancers in children have decreased because of better treatment and survival (right). Incidence rates (numbers of new cases), however, have tended to increase for unknown reasons. (Reliable data on incidence rates only became available beginning in the early 1970s.) Incidence rates can reflect changes in various exposures, and they are affected by changes in how cancers are diagnosed and reported.

The effect of a major cancer risk factor, like smoking, is evident in the historic lung cancer rates. The possible effects of EMF would be mixed with those of many other factors having small or moderate risks to certain segments of the population. The individual contribution of these factors would be difficult to separate in the overall cancer rates.

\section{Q Besides cancer, what other kinds of effects have been reported in epidemiologic studies involving EMF?}

A Several epidemiologic studies have looked for effects of EMF on general health, reproduction, suicide and depression, and hypersensitivity. Most numerous are studies of possible effects on reproduction. Sources of EMF exposure in the reproduction studies included power lines and substations, electric blankets and heated water beds, electric cable ceiling heat, and VDTs (video display terminals). Although evidence is weak for effects from VDTs, guidelines developed in Sweden have been adopted by some makers of video monitors (right).

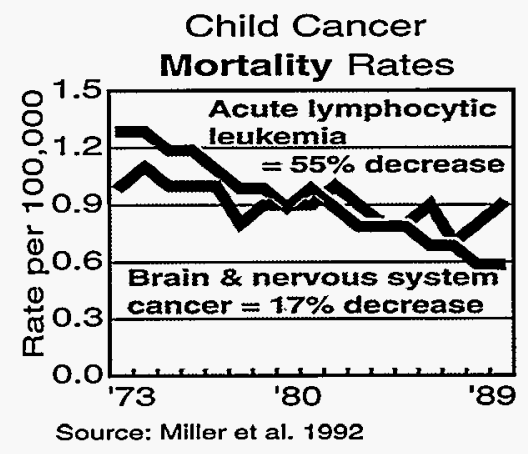

Child Cancer

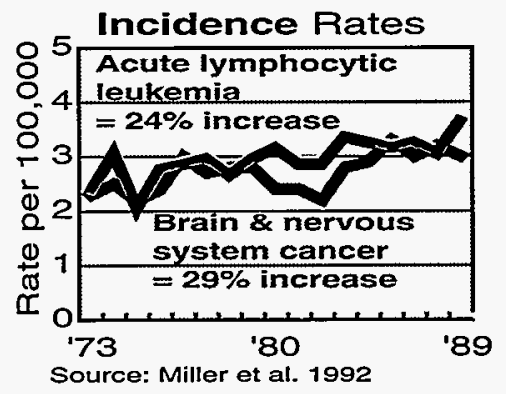

VDT Guidelines From Two

Swedish Organizations

Limits for magnetic fields in the $5 \mathrm{~Hz}$ to $2 \mathrm{kHz}$ range:

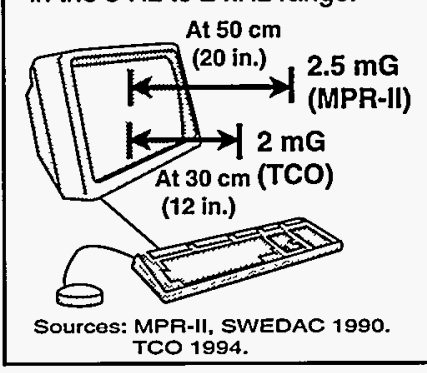


Several studies looked at the overall health of highvoltage electrical workers, and a few looked at the incidence of suicide or depression in people living near transmission lines. Some studies have also investigated the possibility that certain sensitive individuals may experience allergic-type reactions to EMF.

Recent reviews have assessed the kinds of EMF research listed above. Typically, the reviews conclude that many of the studies have methodological problems such as small sample sizes. To date, there is only weak evidence that EMF cause the type of health problems described above.

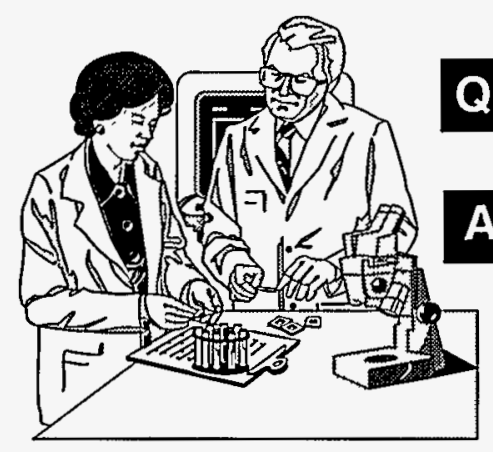

Cancer

Laboratory studies have shown that it is unlikely that EMF can initiate the cancer process. Some studies suggest, however, that power-frequency EMF may promote development of certain existing cancers. Several large-scale studies of laboratory rodents are underway which are testing this hypothesis.
Q What kinds of effects of EMF have been reported in laboratory studies?

A Several kinds of biological effects have been reported in studies of electric and/or magnetic fields (page 28). A biological effect is a measurable change in some biological factor. It may or may not have any bearing on health. Overall, effects attributed to EMF have been small and difficult to reproduce. Very specific laboratory conditions are usually needed for effects of EMF to be detected. It is not known how EMF actually cause these effects.

Laboratory studies to date have not answered questions about possible human health effects. These studies are, however, providing clues about how EMF interact with basic biological processes. The cell membrane may be an important site of interaction with induced currents from EMF. 


\section{Some Reported Effects of 60-Hz EMF in Laboratory Studies}

Decrease in bone fracture-healing rate $(E)$

Changes in tumor development $\left(E_{2}, M\right)$

Avoidance of strong fields (E)

Decrease in the hormone melatonin $(E, M)$

Changes in stress hormones (E)

Field detection (E)

Slowing of human heart rate $(E, M)$

Changes in human brain activity $(E, M)$

Source: Laboratory references listed on page 48
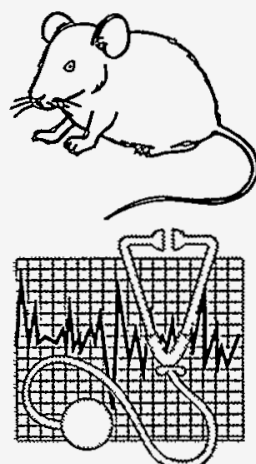

Changes in white blood cell counts $(E)$

Temporary effect on growth $(E, M)$

Changes in behavior tests (E,M)

Changes in biorhythms $(E, M)$

Changes in functions of cells and tissues (E,M)

( $E=$ electric field, $M=$ magnetic field)

\section{Q What about effects of EMF on the hormone melatonin?}

A Melatonin is a hormone produced mainly at night by the pineal, a small gland in the brain. In the 1980 s, scientists found that in rats exposed to $60-\mathrm{Hz}$ electric fields, nighttime melatonin levels were reduced greatly. Other studies have since reported that both $\mathrm{AC}$ and $\mathrm{DC}$ magnetic fields can also affect melatonin levels. Recent studies, however, have not been able to confirm the large effect of electric fields on melatonin. Also, melatonin levels were not affected in sheep raised for nearly a year in the EMF directly beneath a BPA $500-\mathrm{kV}$ transmission line. The Midwest Research Institute has begun a new study aimed at determining whether $60-\mathrm{Hz}$ magnetic fields can affect melatonin levels in people. See page 29 for more on melatonin.

\begin{abstract}
Melatonin and Cancer One reason scientists are interested in melatonin is that it could help explain results of some EMF epidemiological studies. Melatonin seems to have a natural ability to slow the growth of some cancers, including breast cancer. If power-frequency EMF can affect melatonin in humans, this could be a mechanism to explain results of some EMF studies of breast.cancer.
\end{abstract}




\section{Melatonin}

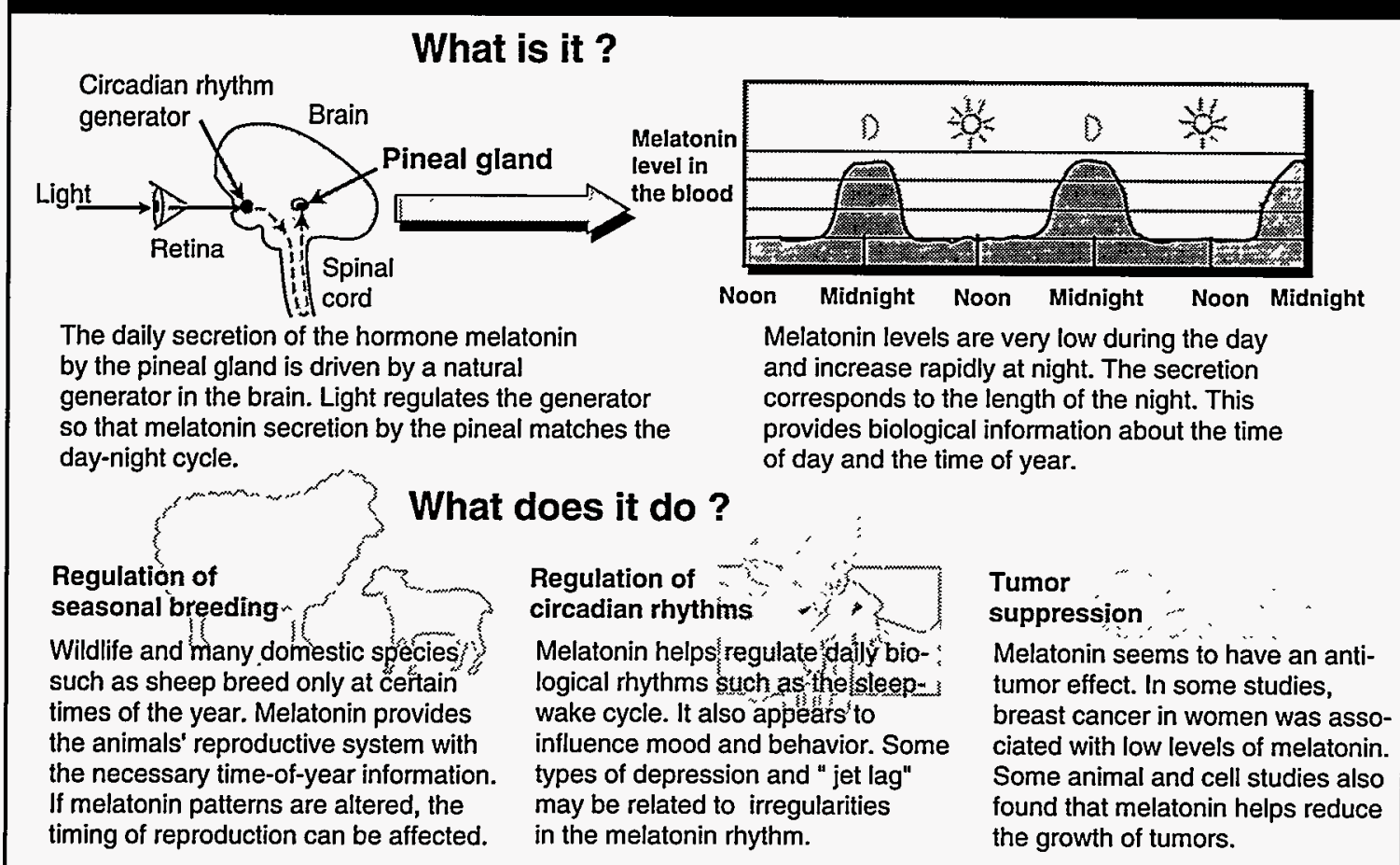

\section{What affects it ?}

Under certain conditions, night-time melatonin can be depressed by light, stress, alcohol, and EMF.

\section{Laboratory rats}

Studies in the 1980s first reported that $60 ; \mathrm{Hz}$-electric fields reduçed greally pineal melatonin in rats, Newer studies have not been able to'repéat these. findings. Some studies have reported that $50 / 60-\mathrm{Hz}$ magnetic fields affect melatonin, but other studies did not find this effect.
Hamsters

Two studies found that 60-Hz magnetic fields reduce of melatonini levels in hámsters. Exposuré to the ffield occurted for only 15 minùtes during the light period.

Sheep
A study foùnd ho effects
of EMF on melatonin jn
sheep raised beneath a
BPA $500-k V$ transmission
line in Oregon: There
wereialso no effects
on reproductive cycles,
however, a possible
effect on the immune
system was found.

A stuady foùnd ho effects of EMF on melatonin in BṔ 500-kV transmis line in Oregon: There wereálso no effects however, a possible system was found.
Humans

One study suggested melatonin was'aiffected in certain women using specially made electric blankets A study is under way to see; whether magnetic fields âffect melatonin in people under laboratory conditions. A study in Seattle is'attempting to see whether breast cancer in women is related to EMF. is 


\section{Q Are more studies of EMF being done?}

A Yes, worldwide, there are over 200 studies underway or planned involving magnetic and/or electric fields. These include epidemiologic, laboratory, environmental, and engineering studies. Many of these involve some aspect of cancer development. These studies are sponsored by Federal and local government agencies and by private organizations, including electric utilities and appliance manufac-

EMF studies are being done in at least 22 countries.

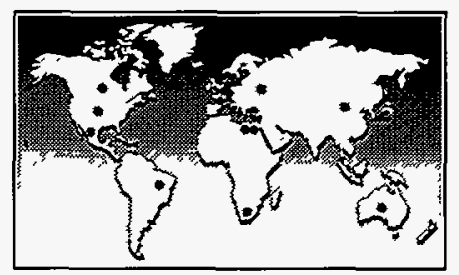
turers.

The 1992 National Energy Policy Act included a provision for a 5-year, $\$ 65$-million program of research and information dissemination on EMF. The program will be supported by both Federal and matching voluntary private funds. The program is being coordinated by the U.S. Department of Energy and the National Institute of Environmental Health Sciences.

\section{Q Is it safe to live close to a transmission line?}

A Living close to a transmission line can increase your overall exposure to EMF (see page 12). As discussed above, with the exception of Sweden, government health or safety organizations worldwide have reportedly not assumed or concluded that EMF cause cancer or other health effects.

It is generally acknowledged that several studies have reported increased cancer risks, especially for children living close to high-current power lines.

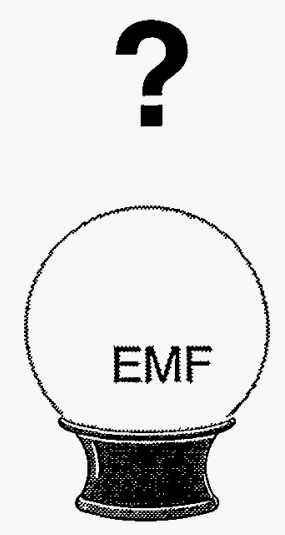


Although these studies suggest potential risks, scientists do not yet know whether EMF, other factors, or methodological problems are responsible for the findings of these studies.

It is possible that future studies will provide sufficient information to establish whether or not EMF are a hazard to human health. The newer studies may also show that factors other than EMF were responsible for effects reported in earlier studies. It is also possible that, even with more research, there will be no scientific resolution to the EMF issue in the near future.

The answer to this question, therefore, involves: (1) a great deal of judgment about the meaning of existing scientific evidence, (2) speculation about the possible results of future studies, and (3) individual perception about the relative importance of various potential health risks.

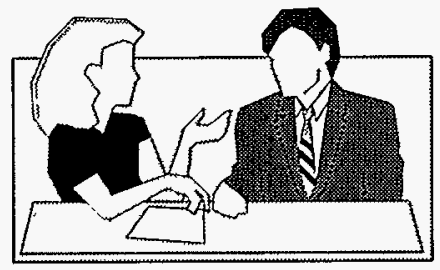

During this period of uncertainty, there are some things that you can do to help answer this question:

1. Become well-informed about the EMF issue by reading and talking with people from a variety of sources.

2. Find out about the EMF levels produced by the particular transmission line you are interested in. (You may be far enough away from the line so that EMF levels are very low-see page 9.) 
3. Try to place EMF in perspective with other potential and real health risks that are important to you (see BPA publication number 4 listed on page 40 for information on various risks).

\section{Q What can be done to limit EMF exposures?}

A While scientific research is ongoing, there are a number of ways that individuals and organizations can reduce exposures to EMF if they choose to do so. Some methods entail little or no cost, while others could be very expensive. Because scientists are still trying to determine whether or not EMF are hazardous to health, it is not clear how much should be done at this time to reduce exposures. Below are some examples of general ways to reduce exposures to EMF.

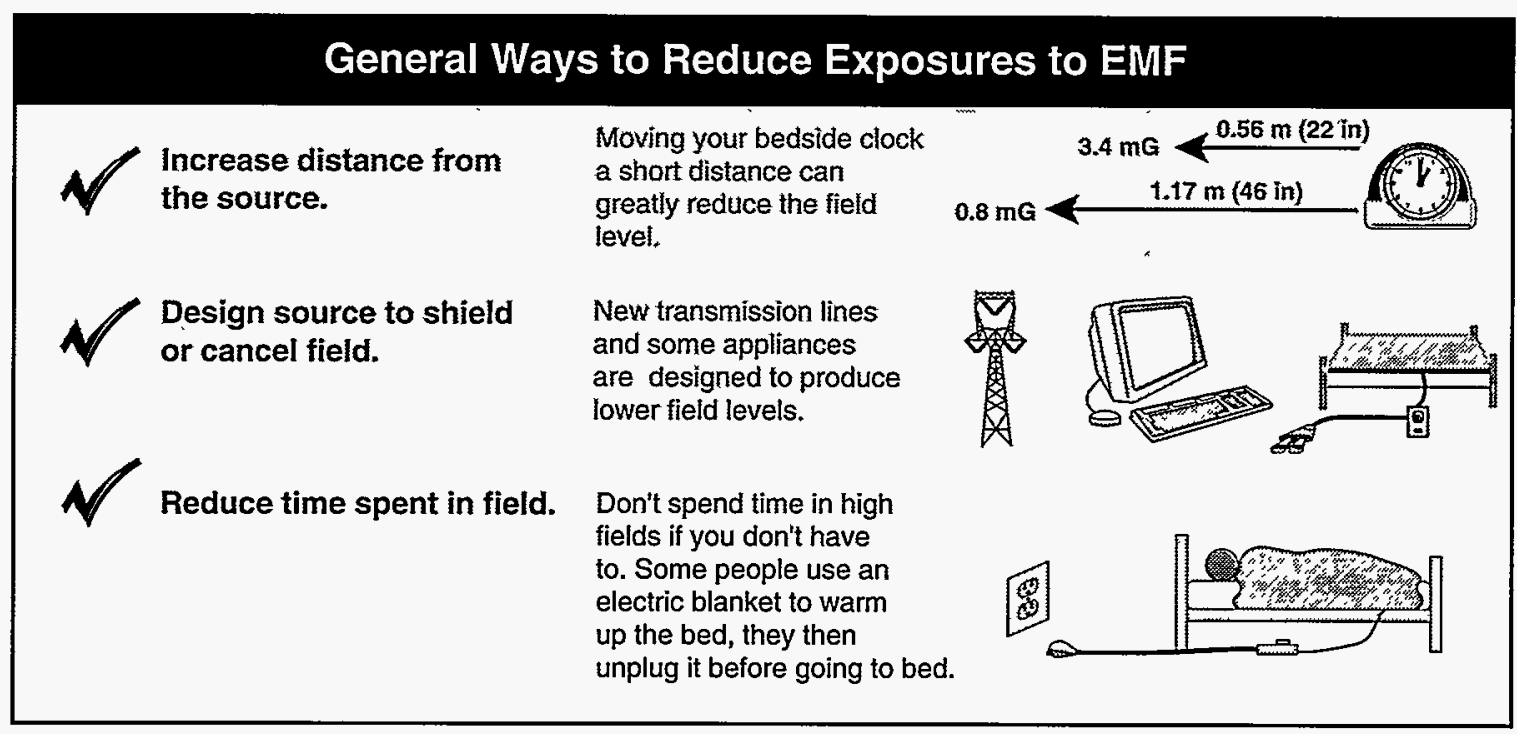


Q How can I find out how strong the EMF are where I live or work?

A You can get a general idea about magnetic field levels around various kinds of electrical appliances from the figure on page 8. Also, page 9 shows typical EMF at various distances from BPA transmission lines. If you want more specific information about EMF from a particular BPA transmission line, contact your nearest BPA office (see page 41). If the line that you are interested in is not owned by BPA, you should contact the utility that operates the line.

If you want to make your own field measurements, there are several companies that sell gaussmeters which measure $60-\mathrm{Hz}$ magnetic fields. Some of these meters will also measure electric fields. For information on these meters, contact BPA or your local utility.

Several companies make small meters that measure powerfrequency magnetic fields.

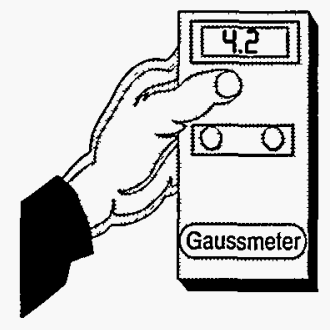


Q How does the magnetic field throughout my home compare to other homes?

A As a comparison with the magnetic field throughout your home, see the figure below. It summarizes spot measurements of magnetic fields made in the center of rooms in 992 homes throughout the U.S. The all-room mean magnetic field for all homes was $0.9 \mathrm{mG}$. Only $15 \%$ of the homes had mean magnetic fields greater than $2.1 \mathrm{mG}$. The measurements were made away from electrical appliances, so they primarily reflect the fields from outside distribution lines and electrical grounding sources.

The study of 992 homes was not designed to measure people's actual exposure to magnetic fields. Instead, it focused on identifying internal and external sources of these fields in the home. Your exposure to magnetic fields depends on how much time you spend near various sources, and on the strength of the fields produced by the sources (see pages 7 through 12).

\section{Magnetic Field Measured in 992 Homes}

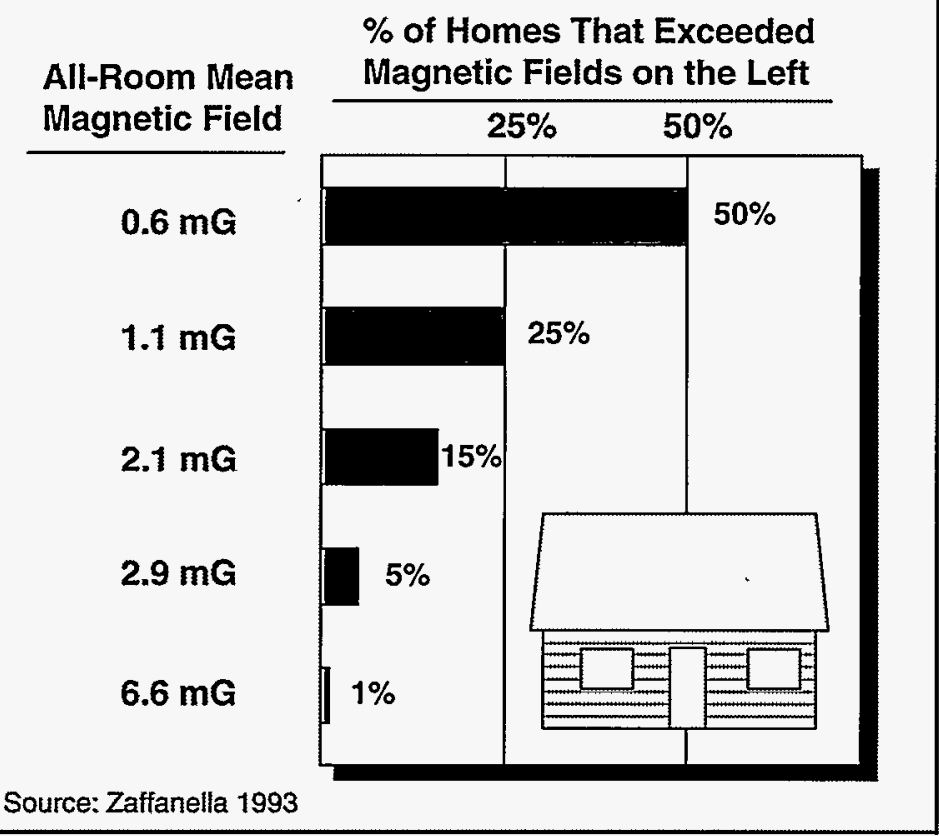




\section{POWER LINES AND SAFETY}

The previous questions and answers dealt with possible health effects of EMF. When electric utilities refer to safety near power lines, they mean prevention of electric shocks which could seriously injure or kill people or animals. Safety hazards are well understood and they are managed in two basic ways: (1) by designing lines to minimize public exposure to these hazards, and (2) by educating people who live or work near the lines about safety hazards.

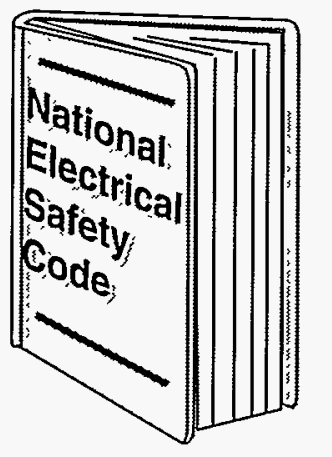

People can live safely around power lines so long as care is taken. BPA and local utilities must be careful about how and where lines are built and maintained. BPA designs and builds transmission lines in accordance with the National Electrical Safety Code. The code specifies how far transmission line conductors must be from the ground or from adjacent buildings or trees. BPA usually determines how wide its rights-of-way ${ }^{*}$ must be on the basis of those safe clearance distances.

\footnotetext{
* The right-of-way is a strip of land for which a utility acquires permanent rights which allow the utility to build, operate, and maintain its transmission lines safely and reliably. These rights enable the utility to keep the right-of-way clear of trees, structures, and fire hazards that could compromise the safety of employees and the public.
} 
The National Electrical Safety Code alone cannot guarantee complete safety. People must be careful around power lines. These lines can cause serious electric shocks if a person or anything he or she is carrying (such as an irrigation pipe or a ladder) comes too close to the line. If this happens, the high voltage on the line can cause the electricity to "arc" over to the nearby object; you would be seriously injured or killed. A BPA booklet, Living and Working Around High-Voltage Power Lines, describes safe practices near power lines (page 40).

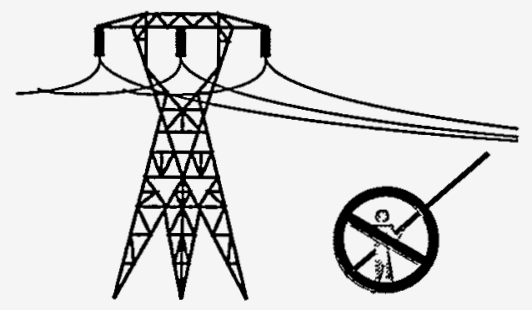

For safety purposes, buildings should never be located within transmission line rights-of-way. If a homeowner is not sure where the edge of the rightof-way is, he or she should check with the utility, planning department, or zoning department before starting to build anything close to a transmission line. A publication from BPA, called Landowner's Guide to Use of BPA Rights-of-way, may be helpful in learning about rights-of-way. (See page 41 on how to obtain BPA publications.)

\section{Q Can I receive shocks from objects near transmission lines?}

A Yes, AC lines create voltages on nearby conducting objects-anything from trees and fences to people and animals. One effect associated with large transmission lines (usually with voltages greater than $230 \mathrm{kV}$ ) is the "nuisance shock." For instance, suppose a voltage were created on wire fencing 
mounted on dry wood posts ( insulating it from the ground). If you were to touch the fence, you could receive an annoying shock, much like the shock you can get from touching a door knob after walking across a rug. To prevent nuisance shocks, metal fences, gutters, buildings, or other such objects near transmission lines are grounded if they pose a problem.

Typical Situations Where Nuisance Shocks Can
Occur From Voltages on Objects
Near Transmission Lines




\section{Q What is BPA doing about the EMF issue?}

A BPA has been reviewing and conducting research on EMF since the mid-1970s. Because of public concern and scientific uncertainty, in 1987-88 BPA conducted a review of how the agency was dealing with the EMF issue. As a result, in 1988 BPA adopted interim guidelines on EMF. These included a provision that EMF exposures of employees and the public should not be increased if practical alternatives can be found. BPA's right-of-way management practice was revised in 1990 to reflect

BPA transmits electric power from Federal hydroelectric dams in the Pacific Northwest.

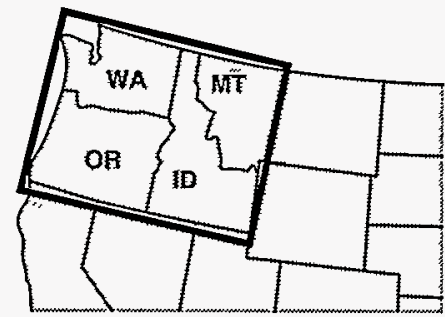
public concerns over EMF. BPA no longer encourages new uses of its transmission rights-of-way which might increase public exposure to EMF.

\section{Summary of BPA Interim Guidelines on EMF}

Because of public concern and scientific uncertainty about EMF, in 1988 BPA adopted interim guidelines for addressing EMF issues. The guidelines were revised in 1992, and they will be reviewed approximately every 2 years. The full guidelines can be found in BPA publication number 4 listed on page 40 . Below is a summary.

It is not reasonable to adopt numerical health standards for EMF at this time. BPA will be consistent with EMF standards adopted by states in our service area to the maximum extent practicable.

BPA will continue to support research efforts dealing with EMF issues.

For new transmission facilities, EMF exposure shall be a major decision factor, and we will attempt to keep EMF exposures as low as reasonably achievable.

Where practical alternatives exist, public and employee exposure to EMF should not be increased.

BPA employees will be kept informed on current research, and ways will be explored to reduce EMF exposures on the job.

BPA will continue to inform and involve the public in decisions and issues involving EMF produced by BPA transmission facilities. 
Such uses include parks, playgrounds, and parking lots. Because of increasing interest in EMF, BPA adopted revised guidelines on EMF in 1992. Exposure to EMF is now considered a major factor that BPA evaluates when new transmission lines and substations are proposed. As a general goal, we attempt to keep new EMF exposures as low as reasonably achievable.

\section{Q What would BPA do if EMF were found to} be hazardous to human health?

Are EMF a health hazard ?

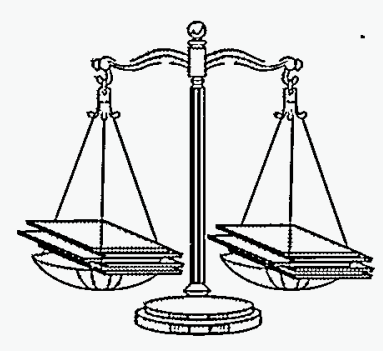

A This would depend on the nature of the hazard and on how the hazard determination was made. A Federal energy, health or environmental agency could direct other agencies such as BPA to adopt specific EMF health standards, guidelines, or mitigation plans. Similarly, BPA could be directed to take specific actions as a result of Federal Executive Office Orders, or as a result of Federal legislation dealing with EMF.

Significant BPA decisions about EMF which might involve major modifications of the existing transmission system, or could cause expansions of existing rights-of-way, could require following procedures of the National Environmental Policy Act (NEPA). NEPA provides BPA's customers and citizens in the Northwest with a formal opportunity to assist BPA in developing and evaluating alternative courses of action. Concern about EMF is a societal issue, and BPA is committed to involving the public in policy discussions about this issue. 


\section{FOR MORE INFORMATION}

\section{From BPA:}

If you want to learn more about health and safety concerns related to transmission lines, the publications below are free from BPA.

\section{Living and Working Around High-Voltage} Power Lines ( 9 pp.)

This short booklet tells you about the safety precautions you should take when you are around a high-voltage line. It deals primarily with ways to prevent electric shock.

Level of

technical detail:

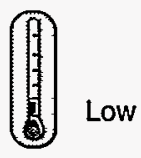

2. What We Know (and don't know) About EMF (brochure)

If you want a short summary of the health issues associated with electric and magnetic fields, you will find it in this publication.

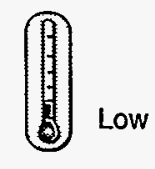

3. Health, Safety and New Electric Power Facilities (9 pp.)

This brochure describes how BPA considers health and safety issues when new electric power facilities are planned.

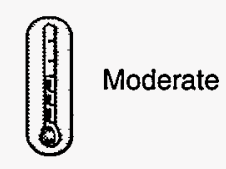

4. Electrical and Biological Effects of Transmission Lines: A Review (107 pp.)

This book contains detailed information about all types of biological and environmental effects of both $\mathrm{AC}$ and DC transmission lines. 
Copies of BPA publications may be ordered by calling BPA's document request line, 800-6224520. You will reach a recorded message. Please ask for the documents you want by name. If you would like to speak with someone, please call our toll-free public involvement line at 800-622-4519. (From outside the U.S. call 503-230-3478.)

Or, call the nearest local BPA office:

Portland (503) $230-4558$

Eugene

(503) $465-6952$

Seattle

(206) $553-4130$

Spokane

(509) 353-2567

Missoula

(406) $329-3060$

Walla Walla

(509) $527-6213$

Idaho Falls

(208) 523-2706

Boise

(208) 334-9137

Washington, DC (202) 586-5640 


\section{Information From Other Sources:}

The U.S. Environmental Protection Agency provides free publications on EMF, contact:

EPA Public Information Center

Washington, D.C. 20460 (202-260-7751)

Publications on EMF are available for sale from:

Carnegie Mellon

University

Depart. of Engineering

and Public Policy, $\mathrm{P}$

Attention: EMF

129 Baker Hall

Pittsburgh, PA 15213

(412-268-2670)

Edison Electric Institute

Washington, DC

(202-508-5424)
Culver Company

316 Merrimac Street

Newburyport, MA

01950

(800-428-5837)

\section{REFERENCES}

The references beginning on page 43 are grouped by the major topics covered in this publication. Most of these should be available in technical libraries such as at universities or medical schools. If you need to see a particular reference and you can't find it at the library, you may want to call BPA's toll-free public involvement line at 800-622-4519. Ask to speak with an EMF specialist. The specialist may be able to help you obtain the reference. 


\section{EMF Levels and Exposures}

Bowman, J.D. et al. 1992. Electric and Magnetic Field Exposure, Chemical Exposure, and Leukemia Risk in "Electrical" Occupations. Prepared by University of Southern California, for Electric Power Research Institute, Palo Alto, CA.

Bracken, T. D. and R. F. Rankin (Principal Investigators). 1994. EMDEX Project Residential Study Final Report. (In press) Prepared by T. Dan Bracken, Inc., for Electric Power Research Institute, Palo Alto, CA.

Gauger, J. R. 1985. Household Appliance Magnetic Field Survey. IEEE Transactions on Power Apparatus and Systems PAS 104 (9):2436-2444.

Stearns, R.D., M.W. Tuominen, and V.L. Chartier. 1992. Magnetic Field Characterization for the Bonneville Power Administration's 500, 230, and 115-kV Transmission Line Systems. Abstract P-26. The Annual Review of Research on Biological Effects of Electric and Magnetic Fields from the Generation, Delivery and Use of Electricity. W/L Associates, LTD. Frederick, MD. (Available from BPA.)

Zaffanella, L.E. (Principal Investigator). 1993. Survey of Residential Magnetic Field Sources Final Report TR-102759 (2 vols.). Prepared by High Voltage Transmission Research Center, for Electric Power Research Institute, Palo Alto, CA.

\section{EMF Standards and Regulations}

American Conference of Governmental Industrial Hygienists (ACGIH). 1993. 1993-1994 Threshold Limit Values for Chemical Substances and Physical Agents and Biological Exposure Indices. ACGIH, Cincinnati, $\mathrm{OH}$.

Electro-Magnetic Health Effects Committee. 1992. Regulatory Issues, Chapter 6.0, in, Health Effects of Exposure to Powerline-Frequency Electric and Magnetic Fields. Public Utility Commission of Texas, Austin, TX.

International Non-ionizing Radiation Committee of the International Radiation Protection Association (IRPA / INIRC). 1990. Interim Guidelines on Limits of Exposure to $50 / 60 \mathrm{~Hz}$ Electric and Magnetic Fields. Health Physics 58:113-122.

SWEDAC. 1990. User's Handbook for Evaluating Visual Display Units. MPR 1990:10 1990-1231. Swedish Board for Technical Assistance (SWEDAC). Borås, Sweden.

Tjänstemännens Central Organisation (TCO). (Swedish Confederation of Professional Employees). 1994. Screen Facts. Stockholm. (TCO Information Center, Chicago, IL). 


\section{Residential Childhood Cancer Studies \\ (In Chronological Order)}

Wertheimer N. and E. Leeper. 1979. Electrical Wiring Configurations and Childhood Cancer. American Journal of Epidemiology 109:273-284.

Fulton J.P., S. Cobb, L. Preble, L. Leone, and E. Forman. 1980. Electrical Wiring Configurations and Childhood Leukemia in Rhode Island. American Journal of Epidemiology 111:292-296.

Tomenius L. 1986. 50-Hz Electromagnetic Environment and the Incidence of Childhood Tumors in Stockholm County. Bioelectromagnetics 7:191-207.

Savitz D.A., H. Wachtel, F.A. Barnes, E.M. John, and J.G. Trrdik. 1988. Case-Control Study of Childhood Cancer and Exposure to 60- $\mathrm{Hz}$ Magnetic Fields. American Journal of Epidemiology 128:21-38.

Coleman M.P., C.M.J. Bell, H.L. Taylor, and M.P. Zakelj. 1989. Leukaemia and Residence Near Electricity Transmission Equipment: A Case-Control Study. British Journal of Cancer 60:793-798.

Lin R.S. and P.Y. Lu. 1989. An Epidemiologic Study of Childhood Cancer in Relation to Residential Exposure to Electromagnetic Fields. DOE Contractors' Review. Abstract A-40. The Annual Review of Research on Biological Effects of Electric and Magnetic Fields From the Generation, Delivery, and Use of Electricity. W/L Associates, LTD. Frederick, MD.

Myers A., A.D. Clayden, R.A. Cartwright, and S.C. Cartwright. 1990. Childhood Cancer and Overhead Powerlines: A Case-Control Study. British Journal of Cancer 62:1008-1014.

London S., D.C. Thomas, J.D. Bowman, E. Sobel, T.C. Cheng, and J.M. Peters. 1991. Exposure to Residential Electric and Magnetic Fields and Risk of Childhood Leukemia. American Journal of Epidemiology 134:923-937.

Lowenthal R.M., J.B. Panton, M.J. Baikie, and J.N. Lickiss. 1991. Exposure to High Tension Power Lines and Childhood Leukaemia: a Pilot Study. The Medical Journal of Australia 155:347.

Feychting M. and A. Ahlbom. 1993. Magnetic Fields and Cancer in Children Residing Near Swedish High-Voltage Power Lines. American Journal of Epidemiology 138:467-481.

Olsen J.H., A. Nielsen, and G. Schulgen. 1993. Residence Near High Voltage Facilities and the Risk of Cancer in Children. British Medical Journal 307:891-895.

Verkasalo P. K., et al. 1993. Risk of Cancer in Finnish Children Living Close to Power Lines. British Medical Journal 307:895-899. 
Petridou E., et al. 1993. Age of Exposure to Infections and Risk of Childhood Leukaemia. British Medical Journal 307:774.

Fajardo-Gutiérrez A., et al. 1993. Close Residence 'to High Electric Voltage Lines and its Association With Children With Leukemia. (In Spanish) Bol Med Infant Mex 50:32-38.

Ahlbom A., M. Feychting, M. Koskenvuo, J.H. Olsen, E. Pukkala, G. Schulgen, and P. Verkasalo. 1993. Electromagnetic Fields and Childhood Cancer. Lancet:342:1295-1296.

\section{Residential Adult Cancer Studies (In Chronological Order)}

Wertheimer N. and E. Leeper. 1982. Adult Cancer Related to Electrical Wires Near the Home. International Journal of Epidemiology 11:345-355.

McDowall M.E. 1986. Mortality of Persons Resident in the Vicinity of Electricity Transmission Facilities. British Journal of Cancer 53:271-279.

Severson R.K., R.G. Stevens, W.T. Kaune, D.B. Thomas, L. Heuser, S. Davis, and L.E. Sever. 1988. Acute Nonlymphocytic Leukemia and Residential Exposure to Power Frequency Magnetic Fields. American Journal of Epidemiology 128:10-20.

Coleman M.P., C.M.J. Bell, H.L. Taylor, and M.P. Zakelj. 1989. Leukaemia and Residence Near Electricity Transmission Equipment: A Case-Control Study. British Journal of Cancer 60:793-798.

Youngson J.H.A.M., A.D. Clayden, A. Myers, and R.A. Cartwright. 1991. A Case-Control Study of Adult Haematological Malignancies in Relation to Overhead Powerlines. British Journal of Cancer 63:977-985.

Eriksson M. and M. Karlsson. 1992. Occupational and Other Environmental Factors and Multiple Myeloma: a Population Based Case-Control Study. British Journal of Industrial Medicine 49:95-103.

Feychting M. and A. Ahlbom. 1992. Magnetic Fields and Cancer in People Residing Near Swedish High Voltage Power Lines. Institute of Environmental Medicine, Karolinska Institute, Stockholm, Sweden.

Schreiber G.H., G.M.H. Swaen, J.M.M. Meijers, J.J.M. Slangen, and F. Sturmans. 1993. Cancer Mortality and Residence Near Electricity Transmission Equipment: A Retrospective Cohort Study. International Journal of Epidemiology 22:9-15. 


\section{Cancer Clusters}

Anonymous. 1990. State Health Studies in Connecticut and North Carolina Refute Brodeur's "Cancer Clusters." Transmission/Distribution Health \& Safety Report 8:6,9-10.

Brodeur, P. 1993. The Great Power-Line Cover-Up. Little, Brown Co., New York.

Neutra R.R., and E. Glazer. 1993. An Evaluation of an Alleged Cancer Cluster Among Teachers at the Slater School Between 1973 and 1992. California Department of Health Services, Berkeley, California.

Several papers on the clustering of health events can also be found in the American Journal of Epidemiology, Volume 132:Supplement, June, 1990.

\section{Occupational EMF Cancer Studies}

Summaries of most of these studies can be found in the following two reviews:

Electro-Magnetic Health Effects Committee. 1992. Regulatory Issues, Chapter 6.0, in, Health Effects of Exposure to Powerline - Frequency Electric and Magnetic Fields. Public Utility Commission of Texas, Austin, TX.

Oak Ridge Associated Universities Panel. 1992. Health Effects of Low-Frequency Electric and Magnetic Fields. ORAU 92/F8. Prepared for the Committee on Interagency Radiation Research and Policy Coordination. U.S. Government Printing Office. GPO \#029-000-00443-9.

Some studies reported since the above reviews:

Floderus B., et al. 1993. Occupational Exposure to Electromagnetic Fields in Relation to Leukemia and Brain Tumors: A Case-Control Study in Sweden. Cancer Causes and Control 4:465-476.

Guénel P., P. Raskmark, J. Bach, and E. Lynge. 1993. Incidence of Cancer in Persons with Occupational Exposure to Electromagnetic Fields in Denmark. British Journal of Industrial Medicine 50:758-764.

Matanoski M.M., et al. 1993. Leukemia in Telephone Linemen. American Journal of Epidemiology 137:609-619.

Sahl J.D., M. A. Kelsh, and Sander Greenland. 1993. Cohort and Nested Case-Control Studies of Hematopoietic Cancers and Brain Cancer Among Electric Utility Workers. Epidemiology 4:104-114. 
Thériault, G., et al. 1994. Cancer Risks Associated with Occupational Exposure to Magnetic Fields Among Utility Workers in Ontario and Quebec, Canada, and France: 1970-1989. American Journal of Epidemiology 139:550-572.

\section{Some National Reviews of EMF Research}

Advisory Group on Non-Ionizing Radiation. 1992. Electromagnetic Fields and Cancer. Vol. 3. No. 1. National Radiological Protection Board. Chilton, Didcot, Oxon, U.K.

Expert Group of the Danish Ministry of Health on Non-ionizing Radiation. 1993. Report on the Risk of Cancer in Children with Homes Exposed to $50 \mathrm{~Hz}$ Magnetic Fields from High-voltage Installations. Danish Ministry of Health, Copenhagen, Denmark.

Guénel, P. and J. Lellouch. 1993. Synthesis of the Literature on Health Effects From Very Low Frequency Electric and Magnetic Fields. INSERM. National Institute of Health and Medical Research. Paris, France.

Oak Ridge Associated Universities Panel. 1992. Health Effects of Low-Frequency Electric and Magnetic Fields. ORAU 92/F8. Prepared for the Committee on Interagency Radiation Research and Policy Coordination. U.S. Government Printing Office. GPO \#029-000-00443-9.

Peach, H.G., W.J. Bonwick, R. Scanlan, and T. Wyse. 1992. Report of the Panel on Electromagnetic Fields and Health to The Victorian Government. Minister of Health. Melbourne, Australia.

Science Advisory Board. 1992. Potential Carcinogenicity of Electric and Magnetic Fields. EPA SAB-RAC-92-013. U.S. Environmental Protection Agency, Washington, D.C.

Swedish National Board for Electrical Safety. 1993. Revised Assessment of Magnetic Fields and Health Hazards. Stockholm, Sweden.

\section{Electricity Use and Cancer Rates}

Jackson, J.D. 1992. Are the Stray 60-Hz electromagnetic Fields Associated With the Distribution and Use of Electric Power a Significant Cause of Cancer? Proceedings of the National Academy of Sciences 89:3508-3510.

Kujawa, L.J., et al. 1992. Electric Power Trends 1992. Arthur Anderson \& Co., Atlanta, Georgia, and Cambridge Energy Research Associates Inc., Cambridge, Massachusetts. 
Miller, B.A., et al. (eds.). 1992. Cancer Statistics Review: 1973-1989. NIH Pub. No. 92-2789. National Cancer Institute, Bethesda, Maryland.

Savitz, D.A. 1993. Health Effects of Low-Frequency Electric and Magnetic Fields. Environmental Science and Technology 27:52-54.

\section{Some Non-Cancer EMF Studies of Humans}

Brent, R.L., W. E. Gordon, W.R. Bennett, and D.A. Beckman. 1993. Reproductive and Teratologic Effects of Electromagnetic Fields. Reproductive Toxicology 7:535-580.

Juutilainen, J., P. Matilainen, S. Saarikoski, E. Laara, and S. Suonio. 1993. Early Pregnancy Loss and Exposure to 50-Hz Magnetic Fields. Bioelectromagnetics 14:229-236.

Lindbohm, M.L., et al. 1992. Magnetic Fields of Video Display Terminals and Spontaneous Abortion. American Journal of Epidemiology 136:1041-1051.

McMahan S., J. Ericson, and J. Meyer. 1994. Depressive Symptomatology in Women and Residential Proximity to High-Voltage Transmission Lines. American Journal of Epidemiology 139:58-63.

Poole, C., et al. 1993. Depressive Symptoms and Headaches in Relation to Proximity to an Alternating-Current Transmission Line Right-of-Way. American Journal of Epidemiology 137:318330.

Rea, W.J., et al. 1991. Electromagnetic Field Sensitivity. Journal of Bioelectricity 10:241-256.

Roman, E., V. Beral, M. Pelerin, and C. Hermon. 1992. Spontaneous Abortion and Work with Visual Display Units. British Journal of Industrial Medicine 49:507-512.

\section{Laboratory EMF Studies}

Results of recent EMF laboratory research can be found in:

Blank, M. (Editor). 1993. Electricity and Magnetism in Biology and Medicine, Review and Research Papers Presented at The First World Congress for Electricity and Magnetism in Biology and Medicine. San Francisco Press, San Francisco, CA.

Oak Ridge Associated Universities Panel. 1992. Health Effects of Low-Frequency Electric and Magnetic Fields. ORAU 92/F8. Prepared for the Committee on Interagency Radiation Research and Policy Coordination. U.S. Government Printing Office. GPO \#029-000-00443-9. 
Frey, A.H. 1993. Electromagnetic Field Interactions with Biological Systems. Federation of American Societies for Experimental Biology Journal (FASEB) 7:272-281.

\section{Studies of Melatonin and EMF}

Lee, J.M., et al. 1993. Melatonin Secretion and Puberty in Female Lambs Exposed to Environmental Electric and Magnetic Fields. Biology of Reproduction 49:857-864.

Liburdy, R.P., T.R. Sloma, R. Sokolic, and P. Yaswen. 1993. ELF Magnetic Fields, Breast Cancer, and Melatonin: $60 \mathrm{~Hz}$ Fields Block Melatonin's Oncostatic Action on ER Breast Cancer Cell Proliferation. Journal of Pineal Research 14:89-97.

Reiter, R.J. 1992. Alterations of the Circadian Melatonin Rhythm by the Electromagnetic Spectrum: A Study in.Environmental Toxicology. Regulatory Toxicology and Pharmacology 15:226-244.

Wilson, B.W., R.G. Stevens, and L.E. Anderson. 1989. Minireview: Neuroendocrine Mediated Effects of Electromagnetic Field Exposure: Possible Role of the Pineal Gland. Life Sciences 45:1319-1332.

\section{Controversy Over the EMF Issue}

Anonymous. 1994. Electromagnetic Fields. Consumer Reports. May.

Brodeur, P. 1993. The Great Power Line Cover-Up. Little, Brown Publishing Co., New York.

Conkling, W. Shocking Charges. 1993. American Health. May.

Cunningham, A.M. 1991. Electromagnetic Fields In Search of the Truth. Popular Science, December.

Stone, R. 1992. Polarized Debate: EMFs and Cancer. Science 258:1724-1725.

Taubes, G. 1993. EMF-Cancer Links: Yes, No, and Maybe. Science 262:649.

Three articles addressing different scientific viewpoints on EMF issues are also contained in Environmental Science and Technology, Volume 27, Number 1, 1993.

News about EMF issues and research can also be found in these newsletters:

EMF Health \& Safety Digest Minneapolis, MN

(612) 623-4600
EMF News

Washington, DC

(202) 508-5425

\section{Microwave News} New York, NY

(212) $517-2800$ 
DOE/BP-2081

Second printing, revised

May 1994, :

3M 